UNIVERSIDADE DE SÃO PAULO

FACULDADE DE ECONOMIA, ADMINISTRAÇÃO E CONTABILIDADE DEPARTAMENTO DE ADMINISTRAÇÃO

PROGRAMA DE PÓS-GRADUAÇÃO EM EMPREENDEDORISMO

ALINHAMENTO INTERNO DE ESTRATÉGIAS EMERGENTES: UM ESTUDO DE CASO EM OPERADORA DE TELECOMUNICAÇÕES

Débora Rodrigues

Orientadora: Prof ${ }^{(a)}$. Dr ${ }^{(a)}$. Luciane Meneguin Ortega

SÃO PAULO 
Prof. Dr. Marco Antonio Zago

Reitor da Universidade de São Paulo

Prof. Dr. Adalberto Américo Fischmann

Diretor da Faculdade de Economia, Administração e Contabilidade

Prof. Dr. Roberto Sbragia

Chefe do Departamento de Administração

Prof. Dr. Martinho Isnard Ribeiro de Almeida

Coordenador do Programa de Mestrado Profissional em Empreendedorismo 


\section{DÉBORA RODRIGUES}

\section{ALINHAMENTO INTERNO DE ESTRATÉGIAS EMERGENTES: UM ESTUDO DE CASO EM OPERADORA DE TELECOMUNICAÇÕES}

Dissertação apresentada ao Programa de PósGraduação em Mestrado Profissional Empreendedorismo do Departamento de Administração da Faculdade de Economia, Administração e Contabilidade da Universidade de São Paulo como requisito parcial para obtenção do título de Mestre em Ciências.

Orientadora: Prof. ${ }^{(a)}$ Dr. ${ }^{(a)}$ Luciane Meneguin Ortega

Versão Corrigida

(versão original disponível na Biblioteca da Faculdade de Economia, Administração e Contabilidade)

\section{São Paulo}



FICHA CATALOGRÁFICA

Elaborada pela Seção de Processamento Técnico do SBD/FEA/USP

Rodrigues, Débora

Alinhamento interno de estratégias emergentes: um estudo de caso em operadora de telecomunicações / Débora Rodrigues. - São Paulo, 2016.

$68 \mathrm{p}$.

Dissertação (Mestrado) - Universidade de São Paulo, 2016.

Orientador: Luciane Meneguin Ortega.

1. Administração 2. Estratégia organizacional 3. Alinhamento estratégico I. Universidade de São Paulo. Faculdade de Economia, Administração e Contabilidade. II. Título.

CDD -658 
Agradeço a todos os professores do Mestrado Profissional em Empreendedorismo por terem me estimulado como pesquisadora, e em especial, ao professor Martinho Isnard por ter acredito e levado a diante este projeto de Mestrado Profissional no qual eu tanto acredito.

À minha família que plantou logo cedo as raízes para que eu conseguisse chegar até aqui. $\mathrm{E}$ aos meus amigos mais queridos que sempre me apoiam!

A todos os colegas de trabalho que construíram comigo as experiências vividas, e em especial aos que aqui cederam seus depoimentos, meu muito obrigada. Não posso deixar de agradecer aos que entenderam muitas vezes minhas ausências e meus horários alternativos para que este mestrado acontecesse.

A toda a $1^{\circ}$ turma do Mestrado Profissional em Empreendedorismo. É uma honra fazer parte de um grupo tão bom quanto este. Meu muito obrigada aos amigos (e orientadores de whatsapp!rs) Milton, Bruno, Gabriel, Irina, Andrea e Renata...A jornada foi mais suave com o apoio de vocês.

E por fim, meu agradecimento mais que especial a minha orientadora e companheira nesta longa jornada, Luciane Meneguin Ortega, pois sem sua preciosa orientação este trabalho não seria possível. 
"O conhecimento era um bem privado, associado ao verbo SABER. Agora, é um bem público ligado ao verbo FAZER". 


\section{RESUMO}

O setor de telecomunicações tem papel essencial na vida das pessoas e na economia mundial, uma vez que este diminui as distâncias e liga qualquer parte do mundo em questão de segundos. No Brasil este mercado é dominado por poucas e grandes empresas que enfrentam o dinamismo da alta competitividade entre elas, e de outras variáveis de mercado como, por exemplo, a agência reguladora do setor, Agência Nacional de Telecomunicações - ANATEL. Este cenário faz com que as empresas do setor sejam constantemente impactadas pela emergência de estratégias, ou seja, estratégias que não foram previamente planejadas. A agilidade no alinhamento destas estratégias se faz essencial para o sucesso da execução das mesmas e instigou esta pesquisa que buscou entender como o alinhamento de estratégias emergentes é feito em uma operadora de telecomunicações. Baseado em um referencial teórico que aprofundou conceitos de estratégia, estratégia emergente e alinhamento estratégico, este estudo de caso realizado em uma operadora de telecomunicações, através da análise de entrevistas aprofundadas sobre a realidade da empresa detectou que quatro características bastante fortes são as bases para que o alinhamento estratégico aconteça nesta empresa: Ausência de processos estruturados, autonomia dos agentes, priorização da agilidade e predisposição ao risco. A descoberta destas características veio ao encontro dos objetivos desta pesquisa, que além de investigar e analisar como o alinhamento de estratégias emergentes é feito em uma operadora de telecomunicações, considerando todas as particularidades do setor, também buscava aprofundar conhecimento sobre as práticas do mercado de telecomunicações no que tange o alinhamento de estratégias emergentes, identificar práticas deste mercado que possam contribuir com melhores práticas em outros mercados e averiguar elementos provenientes da experiência prática que possam contribuir com as teorias exploradas. Por fim, em nome do objetivo específico de apontar com base na teoria oportunidades de melhorias práticas, foram estudados quatro modelos teóricos de alinhamento estratégico, encontrando assim qual seria o que melhor para a realidade da empresa. 


\begin{abstract}
The telecommunications industry plays a key role in people's lives and in the world economy. It reduces distance and connects anywhere in the world in a matter of seconds. In Brazil, this market is dominated by a few large companies that face the dynamism of high competitiveness between them, and the dynamism of other market variables as, for example, the sector's regulatory agency, the National Telecommunications Agency-ANATEL. This scenario ensures the companies within the telecommunications sector are constantly impacted by the emergence of strategies, i.e. strategies that were not planned in advance. The expeditious alignment of these strategies is essential to the success of their implementation and this fact encouraged this research to investigate and understand how the emerging strategies alignment is done in a telecommunications operator. Based on a theoretical framework that deepened on the concepts of strategy, emerging strategy and strategic alignment, this case study held in a telecommunications operator, through the analysis of in-depth interviews about the reality of the company, detected four strong characteristics that are the basis for strategic alignment to happen in this company: autonomy of agents, absence of structured processes, prioritization of expeditiousness, and predisposition to the risk. The discovery of these characteristics came to meet the objectives of this research. In addition to investigating and analyzing how the emerging strategies alignment is done in a telecommunications operator (considering all the particularities of the sector) this research also sought to deepen knowledge of the telecommunication market practices regarding the alignment of emerging strategies, identification of market practices that can contribute to best practices in other markets, and to find out elements from the practical experience that can contribute to the theories explored. Finally, on behalf of the specific goal that is to indicate based on theory, opportunities of practical improvement, four theoretical models of strategic alignment were studied, finding so which is the best for the company reality.
\end{abstract}




\section{SUMÁRIO}

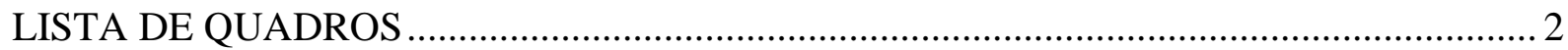

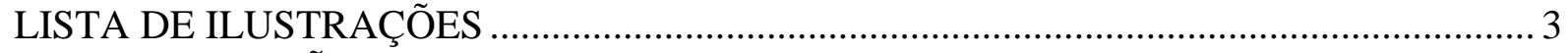

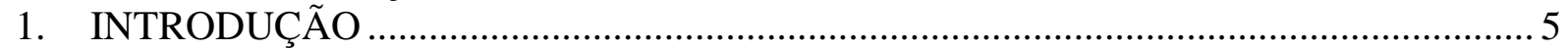

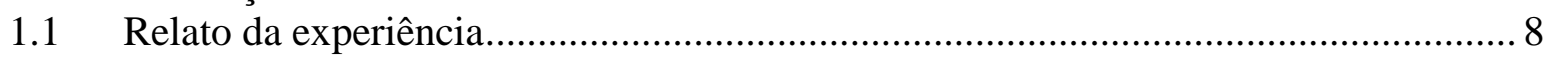

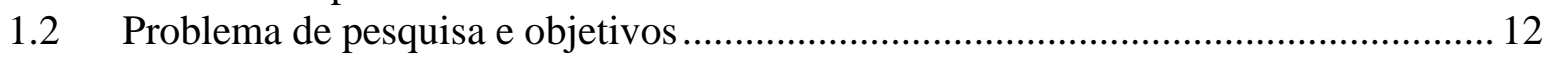

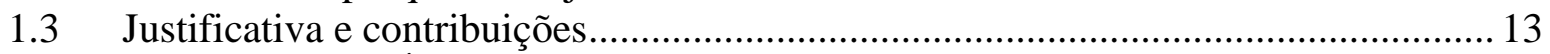

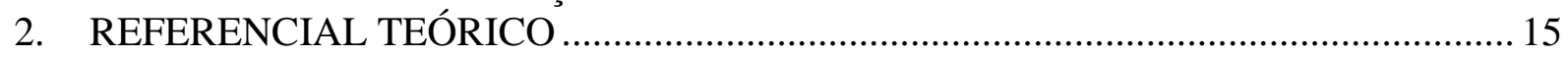

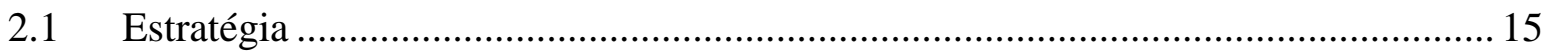

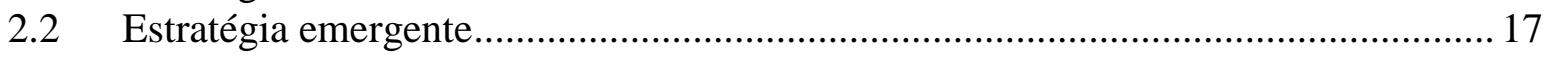

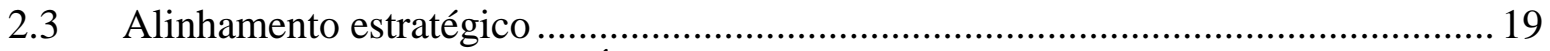

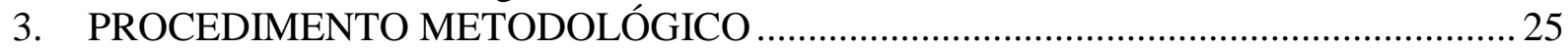

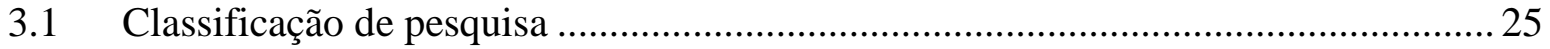

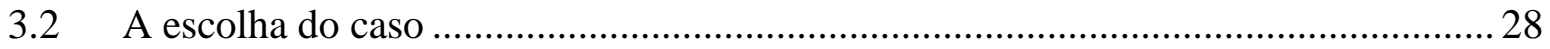

3.3 Definição da amostra e processo de coleta ............................................................. 29

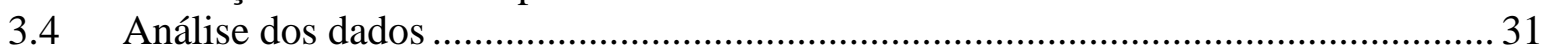

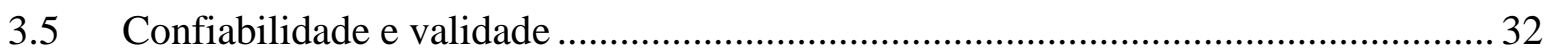

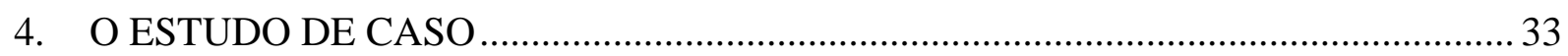

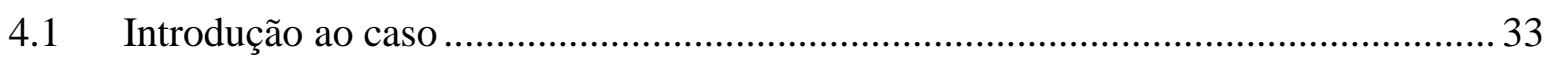

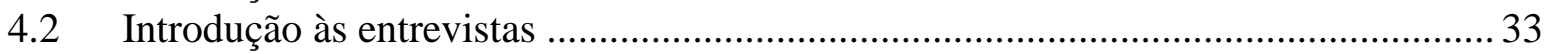

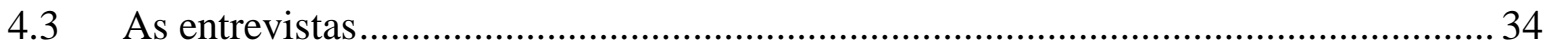

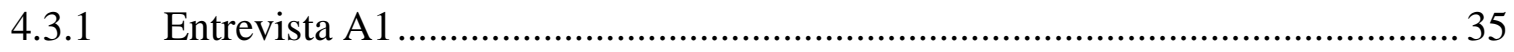

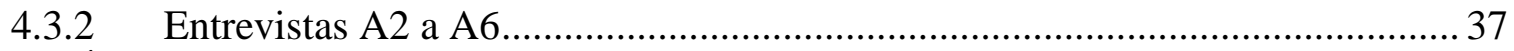

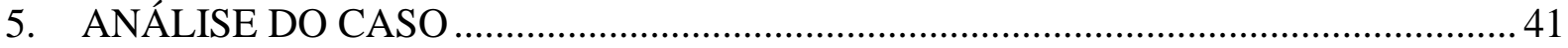

5.1 Análise de modelos teóricos comparados ao estudo de caso....................................... 43

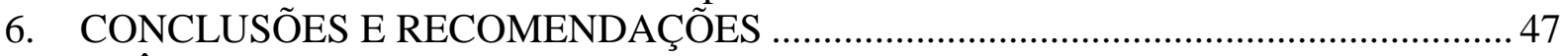

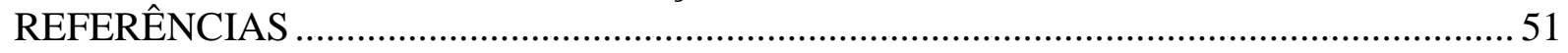

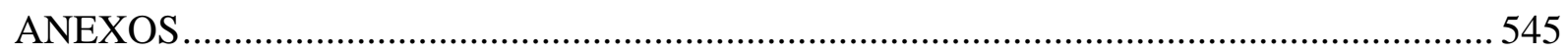




\section{LISTA DE QUADROS}

Quadro 1 - Escolas de pensamento estratégico

Quadro 2 - Análise distintiva dos modelos de alinhamento estratégico interno ....................... 22

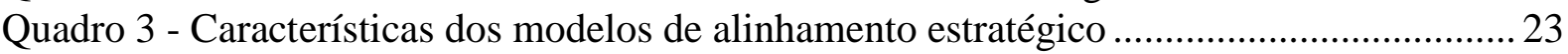

Quadro 4 - Questões direcionadoras de classificação de pesquisa.........................................2 27

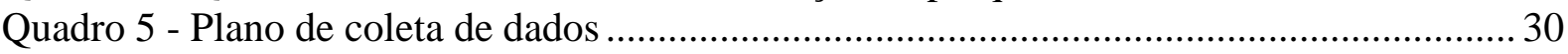

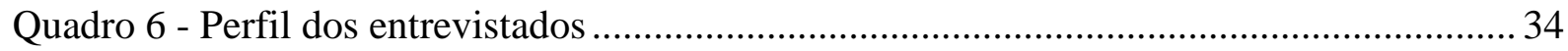




\section{LISTA DE ILUSTRAÇÕES}

Ilustração 1 - Movimentação dos tipos de loja da Empresa de Telecomunicação .................... 10

Ilustração 2 - Novo foco de venda: clientes pessoa jurídica .................................................. 11

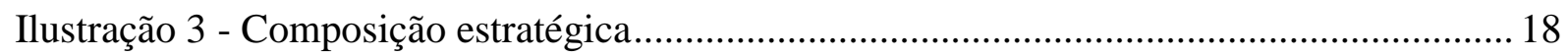

Ilustração 4 - Relação entre práticas de gestão e benefícios .................................................... 20

Ilustração 5 - Princípios da boa pesquisa de ciência social ....................................................... 32

Ilustração 6 - Processo de execução de mudança estratégica em um caso de uma empresa de

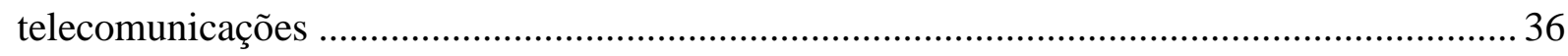

Ilustração 7 - Alinhamento de estratégias emergentes em empresa de Telecomunicações ..... 42 Ilustração 8 - Características impulsionadoras do alinhamento e execução de estratégias

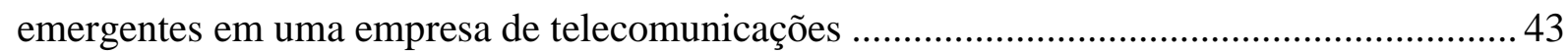

Ilustração 9 - Modelo 4. Organizational Fitness Profiling (OFP) ........................................... 46

Ilustração 10 - Processo de alinhamento de estratégias emergentes e características

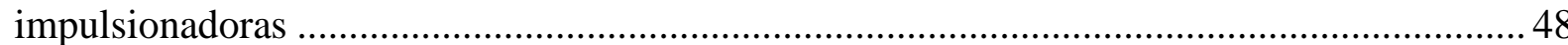




\section{INTRODUÇÃ̃}

O setor de telecomunicações definido como "Setor da economia que engloba os Serviços de Telecomunicações, serviços de valor agregado e produtos utilizados para a prestação destes serviços" (TELEBRASIL, 2014, p. 5), atualmente permeia a vida da maior parte das pessoas e tem um papel relevante na história econômica mundial, uma vez que diminui distâncias em um sistema mundialmente integrado, conforme afirma Neris Jr. et al (2014, p. 398).

Em busca de universalização dos serviços de telecomunicações, países em desenvolvimento, buscaram através da privatização os investimentos em expansão, ou seja, privatizou-se uma infraestrutura inexistente para que empresas privadas a construísse, além de atender a demanda reprimida em grandes centros (COUTINHO, 2005, p. 138).

No Brasil, a privatização aconteceu através da Lei Geral de Telecomunicações (BRASIL, 1997) que colocou a Telecomunicações Brasileiras - Telebrás, estatal de telecomunicações, sob o comando de empresas privadas, objetivando a diminuição da restrição de acesso aos serviços e sua maior democratização. O foco naquele momento (1997) era promover a expansão da telefonia fixa no país, que neste ano atendia 10,3 habitantes a cada 100. Em 2015 a densidade de telefonia fixa atingiu 21,3 habitantes a cada 100, com pico de 22,2 habitantes nos anos de 2012 e 2013 (TELECO, 2016). Quando analisados os dados de densidade de celulares por habilitantes, em 1997 tem-se 2,8 celulares a cada 100 habitantes (ANATEL, 2015), chegando a 124,66 linhas a cada 100 habitantes em abril de 2015 (TELECO, 2016). A diferença comparativa entre estes números demonstra a privatização cumprindo seu papel na expansão do número de acessos.

A Lei que inicia o processo de privatização (BRASIL, 1997) também cria a Agência Nacional de Telecomunicações - ANATEL, responsável por toda a regulamentação e fiscalização do setor não estando vinculada a nenhum outro poder da federação, podendo suas decisões serem questionadas apenas judicialmente. Desde então, a Agência tem plenos poderes sobre o setor e cabe a ela decidir a política nacional sobre o setor, autorizar ou desautorizar empresas a atuarem nele, expedir normas, certificações e exercer as competências legais em matéria de controle, 
prevenção e repressão das infrações da ordem econômica, ressalvadas as pertencentes ao CADE - Conselho Administrativo de Defesa Econômica (BRASIL, 1997).

O setor de telecomunicações é acompanhado por uma série de medidores de desempenho que combinam indicadores de ambiente, como dados populacionais, produto interno bruto, índice de reajuste de tarifas do setor, desempenho do setor nas bolsas de valores, valor das empresas e índices gerais do setor propriamente dito, como número de assinantes de um determinado serviço, penetração dos serviços na população, municípios atendidos, investimentos, dentre outros (TELEBRASIL, 2011).

Sendo assim, todo o trabalho das empresas deve estar em linha com as diretrizes da ANATEL e esta deve ser comunicada dos trabalhos das empresas de forma geral. Como forma de exemplificar o grau de competência da Agência, a Coreia do Sul possui telefones celulares operando em tecnologia 5G, uma tecnologia de rede de comunicação móvel superior à máxima oferecida no Brasil, que tem como principal benefício o aumento de velocidade de transmissão. A expectativa é que esta tecnologia esteja disponível na copa de 2018 na Rússia, nas Olimpíadas de Tóquio em 2020 e na Europa em 2022 segundo Suzuki (2014). Neste cenário, segundo a Lei Geral de Telecomunicações (BRASIL, 1997) cabe a ANATEL decidir se esta tecnologia seria oferecida no Brasil ou não. Uma vez que ela decidisse por oferecer esta tecnologia, seria aberto um leilão para as empresas interessadas em operá-la. Empresas que oferecem equipamentos desde aparelhos de celular, até equipamentos de transmissão de rede devem homologar estes aparelhos junto a ANATEL para que possam fornecê-los às operadoras e usuários. Por fim, as operadoras habilitadas no leilão a oferecer esta tecnologia fariam registro junto a Agência dos planos que pretendem ofertar, com nomes, valores e todas as especificações. As empresas também assumem responsabilidades junto à Agência, que se não cumpridas podem fazer com que percam o direito do oferecimento do serviço.

Analisando o mercado de telecomunicações brasileiro, desde a privatização nota-se que uma série de fusões e aquisições ocorreu entre as operadoras tornando o mercado mais concentrado. A diferença de market share ${ }^{1}$, entre o primeiro e o terceiro colocado em telefonia móvel no mês de abril de 2016 no Brasil é de apenas 3,29 pontos percentuais (TELECO, 2016) o que mostra uma rivalidade sem precedentes mundiais, sendo o único país da América Latina a possuir

\footnotetext{
${ }^{1}$ Market Share: Fatia, ou participação de mercado de determinada empresa.
} 
quatro operadoras com market share considerável, acima de 15\%, e cobertura nacional, segundo a Associação Brasileira de Telecomunicações (TELEBRASIL, 2014).

O acompanhamento histórico e de especulações futuras demonstra perspectivas de contínuas movimentações neste sentido, sendo que a maior parte delas ocorre de forma brusca. Como exemplo histórico pode-se citar a empresa Telefônica assumindo o controle da companhia Vivo em 2010 (TELEFÓNICA COMPRA VIVO POR 7,5 BILHÕES DE EUROS, 2010) e a Vivo, marca que o grupo decidiu que prevaleceria no Brasil, comprando a GVT em 2015 (TELEFÔNICA VIVO CONCLUI COMPRA DA GVT, 2015). Como exemplo de especulação futura pode-se acompanhar a possibilidade de fusão entre Oi e Tim (THOMSON; KHRENNIKOV, 2015) e logo em seguida o interesse de fundos americanos na Tim, dada a não concretização da especulação anterior (FRIEDLANDER; WIZIACK, 2016). Ou seja, o mercado se mostra dinâmica e suscetível a muitas mudanças que podem ocorrer de forma repentina.

A alta concentração do mercado faz com que uma movimentação feita por uma das empresas, seja ela de modelo de negócio ou ofertas, exija rápida resposta das empresas concorrentes para que não haja perda de base de clientes.

Além disso, as operadoras de telecomunicações sofrem influências externas com alta frequência o que as obriga a fazer alterações nas próprias estratégias. Alguns exemplos de momentos em que isto, historicamente, aconteceu:

- Desenvolvimento de novas tecnologias, como no oferecimento de tecnologia 4G (ou quarta geração), que demandou alteração na estrutura de rede das operadoras (ARRUDA, 2013);

- Desenvolvimento de aplicativos que alteram a dinâmica de uso de serviços de telecomunicações, como por exemplo, o WhatsApp ${ }^{2}$, dentre outros aplicativos de mesma natureza, aos quais foi atribuída a primeira queda histórica em receita de $\mathrm{SMS}^{3}$ nas operadoras em 2013. Acredita-se que esta queda hoje de 4\% chegará até a 20\% em 2017 (OPERADORAS BUSCAM ALTERNATIVAS PARA SMS, 2014);

\footnotetext{
${ }^{2}$ WhatsApp - Aplicativo de celular que troca de mensagens entre usuários via rede de dados (internet).

${ }^{3}$ SMS - Short Message Service ou serviço de mensagem de texto.
} 
- Decisões judiciais, como quando em Dezembro de 2015 a justiça determinou o bloqueio do Whatsapp no Brasil, exigindo uma rápida resposta das operações de telecomunicações para que este bloqueio acontecesse (WIZIACK, 2015).

Os fatores de influência externa listados anteriormente fazem com que a emergência de estratégias seja constante neste mercado, exigindo das empresas rápidas adaptações às mesmas para que possam prosperar em seus negócios.

As empresas de telecomunicações, por fim, estão sujeitas a alterações estratégias provenientes de sua própria organização, que buscando melhores resultados, altera planos previamente estabelecidos, buscando executá-los da forma mais rápida possível.

\subsection{Relato da experiência}

Inseridas neste contexto, a seguir são descritas duas situações onde estes eventos foram observados diretamente pela pesquisadora e que foram motivadoras para o desenvolvimento da presente pesquisa. A empresa estudada é uma multinacional de telecomunicações que atua em todo o território brasileiro desde os anos 2000 e conta com mais de 10.000 mil funcionários. A empresa é uma das quatro grandes operadoras de telefonia móvel e divide sua área comercial em dois blocos: Vendas para pessoa física e vendas para pessoa jurídica.

O primeiro evento relatado trata de uma alteração do modelo de lojas de telefonia para atendimento de pessoas físicas e o segundo trata da alteração de modelo de venda para pessoas jurídicas.

O movimento da alteração de lojas de telefonia para atendimento de pessoas físicas pôde ser observado, em uma experiência presenciada no ano de 2011 em São Paulo. Neste período o direcionamento da empresa para telefonia móvel e cliente pessoa física era trabalhar com lojas próprias em locais considerados estratégicos e com parceiros credenciados nas demais localidades, para alcançar capilaridade atingindo o maior número de clientes. 
Seguindo uma estratégia espelhada no mercado europeu, onde as lojas de parceiros ofereciam um custo benefício mais vantajoso à empresa, este modelo foi rompido e determinou-se o fechamento das lojas próprias no Brasil. A determinação foi cumprida e por um ano a empresa trabalhou apenas com empresas parceiras se responsabilizando pela venda e serviços de pósvendas. Após este ano de operação os controles feitos pela área de planejamento de vendas da regional São Paulo/Brasil mostravam que as vendas e, principalmente, a satisfação com os serviços de pós-vendas tiveram uma queda considerável desde o fechamento das lojas próprias.

Os números comparativos somados à influência política do diretor regional da área fez com que a matriz da empresa aprovasse um projeto piloto de reabertura de lojas próprias no Estado de São Paulo (SP). O intuito era reavaliar a situação diante do argumento de que no mercado brasileiro as lojas próprias traziam maior benefício do que as lojas dos parceiros.

Um dos pontos de sustentação deste argumento residia na diferença no modelo de gestão dos dois tipos de lojas. Nas lojas próprias os funcionários recebem um salário fixo e remuneração variável, além de serem impactados pelos mecanismos de avaliação da empresa, enquanto os parceiros são remunerados pelas vendas que fazem, o que os desestimula na tratativa dos clientes, principalmente nos serviços de pós venda. Outro ponto a ser considerado é que por mais que a empresa tenha um cuidado com relação a identidade visual, padrão processual e treinamento das equipes de parceiros, tais pontos podem apresentar falhas nestas empresas o que não acontece nas lojas próprias. Estes fatores foram responsáveis pela aprovação do projeto piloto e a regional de São Paulo recebeu em 2011 autorização e orçamento compatível para a retomada das antigas lojas próprias que estavam sendo operadas por parceiros.

Abertas as primeiras lojas estas foram avaliadas quanto ao desempenho e a justificativa para suas aberturas se mostrou verídica: a relação custo x benefício da operação com lojas próprias era melhor que o apresentado por lojas terceirizadas para os pontos de vendas considerados estratégicos; e, um novo projeto de abertura de lojas para o Estado de SP foi aprovado. O próximo passo foi a aprovação pelo comando da empresa de lojas próprias em caráter nacional e esta é a estratégia praticada pela empresa até o ano de 2016.

Este relato, sintetizado na Ilustração 01, apresenta dois momentos onde a empresa teve que se adaptar rapidamente aos novos direcionamentos estratégicos: no primeiro momento a operação 
de lojas teve seu controle repassado às empresas parceiras, e um ano depois, o mesmo canal fez a retomada das lojas para que as mesmas fossem operadas pela própria empresa.

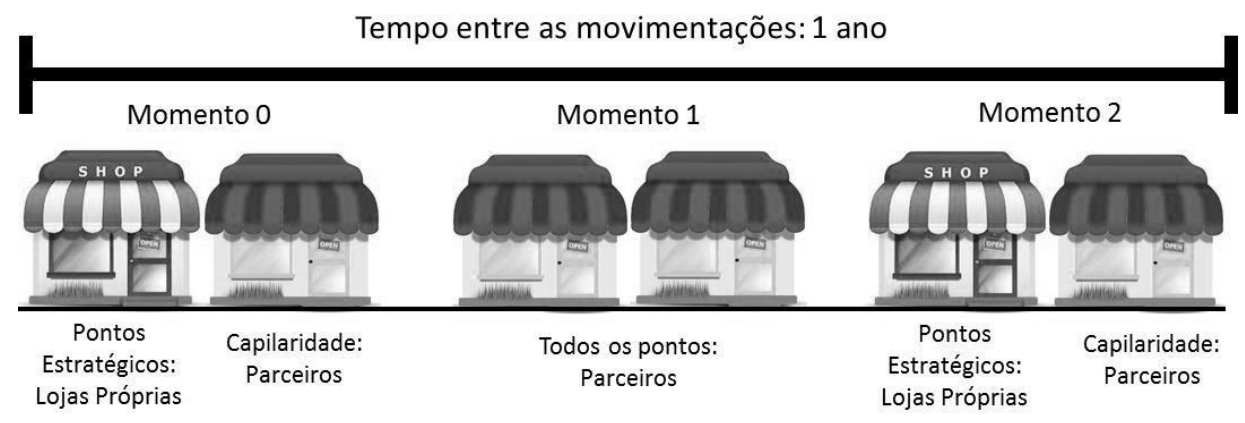

Ilustração 1 - Movimentação dos tipos de loja da Empresa de Telecomunicação

Uma das dificuldades deste processo foi fazer com que a empresa como um todo acompanhasse e contribuísse para esta rápida movimentação. Assim que decidida a retomada das lojas, as áreas responsáveis pelo projeto, comercial e trade marketing, estavam prontamente alinhadas aos objetivos e trabalhando ativamente para o alcance dos mesmos. O desafio aqui é que as áreas de suporte ao projeto, como jurídico, fiscal, recursos humanos, tecnologia da informação, real state, entre outros, acompanhassem a mudança na velocidade e com o foco necessário para que o plano fosse executado da forma e na velocidade adequada.

Uma vez que acontece uma alteração da estratégia, o que é natural no mercado de telecomunicações, afirmação reforçada pelo relato anterior, é necessário que esta seja executada de forma rápida. Se apenas a área propulsora da mudança, neste caso vendas, está alinhada e todas as outras que dão suporte e são essenciais ao sucesso da execução desta estratégia não estão, as chances de sucesso da mesma são bastante diminuídas.

A segunda situação, experimentada no ano de 2014 também em São Paulo, trata da venda de telefonia para clientes pessoa jurídica. Este canal de atendimento tinha como direcionamento principal atender grandes clientes, através de força de vendas própria, deixando o atendimento a pequenas e médias empresas restrito a uma pequena força de vendas terceirizada. A observação de um movimento no mercado de telecomunicações estimulou dois estudos internos ocorridos no âmbito da empresa considerada: um com a área de marketing mostrando o tamanho do mercado potencial de pequenas e médias empresas e outro, com a área de desenvolvimento de canais de vendas, mostrando qual o comportamento da concorrência sobre o mesmo público consumidor. 
Os resultados do primeiro estudo mostraram haver mercado disponível de pequenas e médias empresas e o segundo mostrou que enquanto a empresa focava apenas nos grandes clientes a concorrência havia ampliado em grande número o atendimento às pequenas e médias; além disso, o mercado mostrava uma tendência de convergência de produtos e atendimento, ou seja, empresas oferendo aos seus clientes corporativos tanto telefonia fixa quanto telefonia móvel pelo mesmo canal de atendimento e vendedor.

A estruturação destes trabalhos, iniciados em julho de 2014, foi apresentada a presidência do grupo, que no mês de setembro de 2014 aprovou que o número de vendedores terceirizados fosse quadriplicado e que todo o território nacional passasse a ser atendido. Além disso, estes vendedores além de vender telefonia fixa também passariam a ter autorização para venda de telefonia móvel. A aprovação desta alteração de estratégia, apresentada na Ilustração 02 a seguir, veio com uma contrapartida: todo o novo canal de vendas deveria estar em operação até janeiro de 2015, ou seja, a equipe solicitante teve três meses para executar todo o plano.

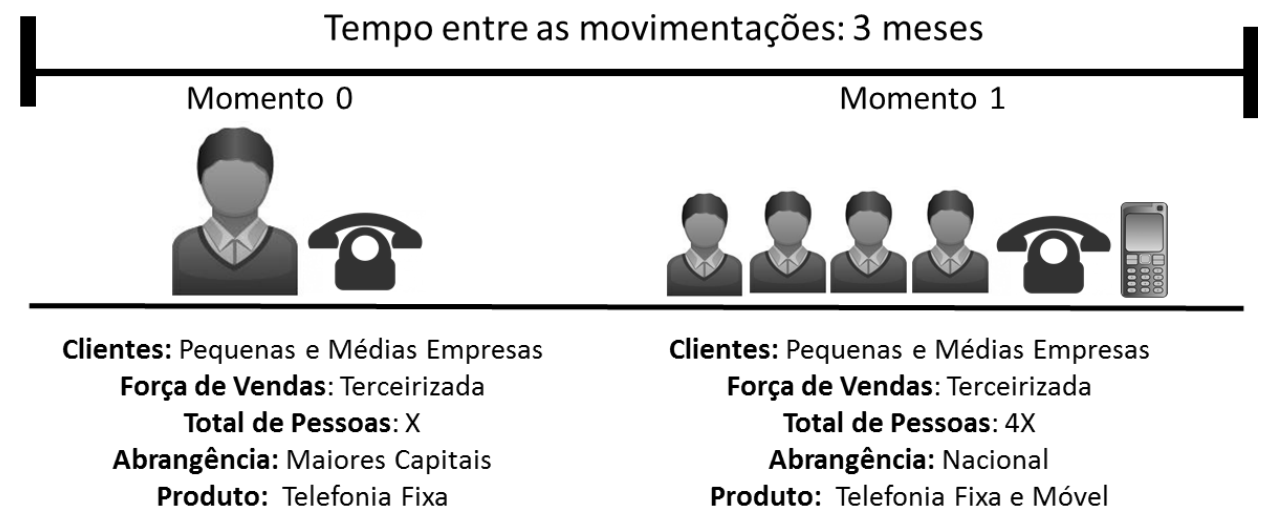

Ilustração 2 - Novo foco de venda: clientes pessoa jurídica

A decisão de alteração do direcionamento estratégico, não implicou somente em uma maior contratação de pessoas, mas sim uma mudança estrutural em toda a empresa, que deveria se preparar para atendimento desta nova equipe, além do atendimento de um novo perfil de clientes, que até o momento era atendido em número não expressivo.

A equipe comercial responsável pela execução deste plano percebeu o mesmo desafio do caso anterior apresentado, ou seja, a necessidade de rápido alinhamento entre as áreas da empresa envolvidas na nova estratégia, principalmente diante do prazo curto que se tinha para que fosse 
posto em prática. Neste caso, o plano foi colocado em prática da forma prevista e em janeiro de 2015 o novo canal estava funcionando segundo o novo padrão desenhado em Setembro de 2014.

As duas situações relatadas apontam para a hipótese de que há um padrão de comportamento comum: estratégias emergindo de diversas fontes que de alguma forma se tornam a estratégia da empresa, exigindo rápido alinhamento interno visando execução.

Estando sempre prontas a estudar novas direções e alterar o rumo do plano sempre que preciso, nota-se nos relatos, duas características: a) exige-se duros esforços das equipes responsáveis pela execução da estratégia, e; b) de alguma forma esta estratégia é alinhada e os objetivos são atingidos.

O dinamismo do mercado de telecomunicações e a necessidade de rápida adaptação das empresas a novas estratégias é a principal justificativa deste trabalho, buscando saber se estas empresas desenvolveram uma melhor forma de alinhar as estratégias que emergem, podendo assim contribuir com a literatura a respeito, ou se, passando por dificuldades neste sentido, possam ser auxiliadas pela literatura.

Como se dá o impacto de mudanças aferidas pela ANATEL, ou pela dinâmica do próprio mercado junto às empresas de telecomunicações? Quais os impactos destas mudanças quando não inseridas no planejamento de uma empresa? Neste cenário, o alinhamento estratégico tornase algo necessário, uma vez que ele precisa acontecer para que a estratégia seja executada. $\mathrm{O}$ alinhamento estratégico em telecomunicações instiga a pesquisa principalmente por tratar de um mercado ágil e sensível às mudanças, e que de alguma forma, consegue sucesso em seus objetivos, dando assim uma importância aumentada à tratativa da problemática abordada.

\subsection{Problema de pesquisa e objetivos}

Diante do cenário exposto, apresenta-se o seguinte problema de pesquisa:

\section{Como o alinhamento de estratégias emergentes é feito em uma operadora de telecomunicações?}


A problemática apresentada e resumida na questão de pesquisa direciona para os seguintes objetivos:

\section{Objetivo principal:}

- Investigar e analisar como o alinhamento de estratégias emergentes é feito em uma operadora de telecomunicações, considerando todas as particularidades do setor.

\section{Objetivos específicos:}

- Identificar os fatores que impulsionam o alinhamento estratégico no setor de telecomunicações, levando em consideração o aproveitamento das estratégias emergentes e agilidade de execução;

- Aprofundar conhecimento sobre as práticas do mercado de telecomunicações no que tange o alinhamento de estratégias emergentes;

- Identificar práticas deste mercado que contribuir com melhores práticas em outros mercados; e;

- Apontar, com base na teoria, elementos que possam aprimorar as atuais práticas de alinhamento estratégico do mercado de telecomunicações.

\subsection{Justificativa e contribuições}

Cumprindo seus objetivos, este trabalho busca contribuir com uma maior interação entre teoria em prática, direcionando o setor estudado a melhores práticas conforme teoria e trazendo à teoria maior conhecimento sobre o setor.

Espera-se também contribuir na alimentação de bases teóricas servindo de comparativo e apoio a outros setores que enfrentem os mesmos desafios, além de auxiliar no desenvolvimento de estudos futuros sobre o tema, fortalecendo assim o arcabouço teórico e as práticas administrativas.

A fim de alcançar os objetivos propostos, o presente trabalho está estruturado para além da introdução, nos seguintes capítulos, a saber: 
- Capítulo 2 - Revisão Teórica: neste capítulo trata-se de um resgate teórico sobre os itens relacionados principalmente ao conceito de estratégias e alinhamento estratégico.

- Capítulo 3 - Procedimento metodológico: contendo a classificação da pesquisa; a escolha do caso; definição da amostra e processo de coleta e análise dos dados.

- Capítulo 4 - Estudo de caso: trata especificamente do estudo de caso escolhido a fim de validar a proposição do objetivo desta pesquisa, histórico e justificativas que foram motivações para o desenvolvimento do presente trabalho.

- Capitulo 5 - Análise do Caso: neste capítulo é apresentada uma análise do estudo de caso;

- Capitulo 6 - Conclusões e recomendações: neste capítulo as considerações finais sobre toda a análise é realizada, assim como as respectivas contribuições da presente pesquisa e propostas para futuros trabalhos.

- Referências Bibliográficas: neste capítulo são descriminadas todas as referências bibliográficas utilizadas pelo trabalho e que dão sustentação para todas as contribuições aqui presentes. 


\section{REFERENCIAL TEÓRICO}

Este capítulo aborda temas relacionados ao objetivo do trabalho como forma de dar subsídios às análises e resultados apresentados.

\subsection{Estratégia}

A palavra estratégia, de origem grega, passou por um processo de evolução que permeia a história da evolução das civilizações, tendo suas primeiras citações por volta de 500 a.C e sempre associado à organização militar (SILVA et al, 2002, p.117). Seu primeiro significado remetia estratégia como sendo a arte de conceber operações de guerra. Evolui passando a englobar todos os recursos que compõem a guerra, sendo a partir daí possível separar a estratégia da guerra propriamente dita.

Projetando para os dias atuais, ao considerar como complexo o ambiente organizacional atual, onde muitas são as variáveis que devem ser consideradas na gestão de uma empresa, a estratégia, ou a arte de dirigir coisas complexas se faz essencial.

Fischmann e Almeida (1991) colocam que toda empresa tem uma estratégia, podendo esta ser definida formal ou informalmente. Sendo formal ela é apresentada através do planejamento estratégico e sendo informal é formada de intuitivamente e baseia-se em experiências, sentimentos e valores.

Para Porter (1996, p. 61-78) estratégia é a criação de uma posição única de valor no mercado e envolve um diferente conjunto de atividades, que devem ser ajustadas para interagirem e se reforçaram mutuamente, além de requerer trade-offs ${ }^{4}$ e escolhas sobre o que não fazer.

Este trabalho adota para estratégia a definição de James B. Quinn:

\footnotetext{
${ }^{4}$ Trade-off: Situação onde há conflito de escolha, ou seja, a escolha de item significa a perda de outro.
} 
Uma estratégia é o padrão ou plano que integra as principais metas, políticas e sequências de ação da organização em um processo coeso. Uma estratégia bem formulada ajuda a organizar e alocar os recursos de uma organização em uma postura única e viável, baseada em suas competências e deficiências internas relativas, mudanças antecipadas no ambiente e movimentos contingentes por parte dos oponentes inteligentes. (QUINN, 2006, p. 29, grifos do autor).

Para Mintzberg et al, (2010, p. 24) a definição de estratégia não é tão simples. Para o autor estratégia requer cinco definições: estratégia é um plano, ou uma direção a ser seguida, estratégia é um padrão, ou seja, um comportamento coerente ao longo do tempo, estratégia é uma posição, ou seja, localização de determinados produtos em determinados mercados, estratégia é uma perspectiva, ou maneira da empresa fazer as coisas, por fim, estratégia é um truque, ou uma manobra especifica de enganar um oponente (no inglês cinco Ps: Plan, pattern, position, perspective e ploy).

Revisando a literatura de administração estratégica, Mintzberg et al (2010, p. 20) apresentam as dez escolas de pensamento sobre a formulação de estratégia. Estas escolas surgiram em estágios diferentes do desenvolvimento da administração estratégica e são apresentadas no Quadro 1:

Quadro 1 - Escolas de pensamento estratégico

\begin{tabular}{|l|l|}
\hline Quadro 1 -Escola & Formulação da Estratégia \\
\hline Escola do Design & Como um processo de concepção \\
\hline Escola do Planejamento & Com um processo formal \\
\hline Escola do Posicionamento & Como um processo analítico \\
\hline Escola Empreendedora & Como um processo visionário \\
\hline Escola Cognitiva & Como um processo mental \\
\hline Escola de Aprendizado & Como um processo emergente \\
\hline Escola do Poder & Como um processo de negociação \\
\hline Escola Cultural & Como um processo coletivo \\
\hline Escola Ambiental & Como um processo reativo \\
\hline Escola de Configuração & Como um processo de transformação \\
\hline
\end{tabular}

FONTE: MINTZBERG et al, 2010, p. 20 (Adaptado).

As escolas do design, planejamento e posicionamento tem natureza prescritiva, ou seja, se preocupam mais em como a estratégia deve ser formulada do que em como elas se formam. A do design formula a estratégia como um processo informal, de concepção. A escola do planejamento formula a estratégia como um processo formal, separado e sistemático. A escola do posicionamento se preocupa com o conteúdo real das estratégias, focando na seleção de posições estratégicas no mercado (MINTZBERG et al, 2010, p. 21). 
As escolas empreendedora, cognitiva, aprendizado, poder e cultural e ambiental tem aspectos específicos de formação da estratégia e se preocupam mais com a descrição de como a estratégia é formulada e menos com o comportamento estratégico ideal. A empreendedora descreve o processo de criação através da visão de um grande líder, a cognitiva usa mensagens de psicologia cognitiva para entrar na mente do estrategista, A escola do aprendizado acredita que a estratégia não deve ser desenvolvida de uma vez só, mas sim emergindo aos poucos, a escola do poder trata a estratégia como um processo de negociação, seja por grupos dentro da organização, seja no ambiente externo. A escola cultural vê o processo estratégico como coletivo e cooperativo e a escola ambiental vê a estratégia como um processo reativo, onde a iniciativa não está na organização, mas no ambiente externo (MINSTZBERG et al, 2010, p. 21).

Por fim, a escola de configuração une processo e formulação de estratégia, conteúdo, estrutura organizacional e contexto, descrevendo o processo estratégico como sendo de transformação (MINTZBERG et al, 2010, p. 22).

Destaca-se aqui a escola do aprendizado, na qual se contempla as estratégias emergentes. Segundo esta escola as estratégias emergem quando as pessoas, individual, mas na maioria das vezes coletivamente aprendem sobre uma situação e a capacidade da organização em lidar com ela, convergindo quanto a padrões de comportamento que funcionam. Os pesquisadores da escola do aprendizado descobriram que redimensionamentos estratégicos importantes raramente eram provenientes de um planejamento estratégico formal, mas sim de pequenas ações e decisões, tomadas por diferentes pessoas. Estas pequenas ações em conjunto produzem a mudança de direção (MINTZBERG et al, 2010, p. 176-222).

\subsection{Estratégia emergente}

Formulada a estratégia, a mesma pode se concretizar ou não. Mintzberg et al (2010, p. 26) sugerem um desdobramento onde:

Intenções plenamente realizadas podem ser chamadas de estratégias deliberadas. As que não foram podem ser chamadas de estratégias não realizadas. (...) Mas há um terceiro caso, que chamamos de estratégia emergente - em que um padrão realizado não era expressamente pretendido. (MINTZBERG et al, 2010, p. 26). 
Sendo assim, estratégia emergente é a estratégia que não faz parte do plano inicial, ou seja, o que é realizado não era expressamente pretendido (MINTZBERG et al, 2010, p. 27).

Enquanto as estratégias deliberadas focam no controle de que intenções iniciais sejam de fato realizadas, as estratégias emergentes focam no aprendizado, pois reconhecem a capacidade de experimentar da empresa (MINTZBERG et al, 2010, p. 187).

A estratégia pode emergir de um agente que concebe uma visão estratégica e a transmite ao chefe, como invenção ou a impõe sobre a organização. Esta estratégia também pode vir da coletividade, onde pessoas interagem e desenvolvem, mesmo que inadvertidamente, um padrão que se torna uma estratégia (MINTZBERG et al, 2010, p. 189).

Os autores colocam ainda que poucas estratégias são puramente deliberadas ou emergentes, pois sendo totalmente deliberadas significariam nenhum aprendizado e, totalmente emergentes, nenhum controle. Diante disso, as estratégias devem se compor, conforme Ilustração 3, não sendo as estratégias emergentes necessariamente más, nem as estratégias deliberadas necessariamente boas (MINTZBERG et al, 2010, p. 27).

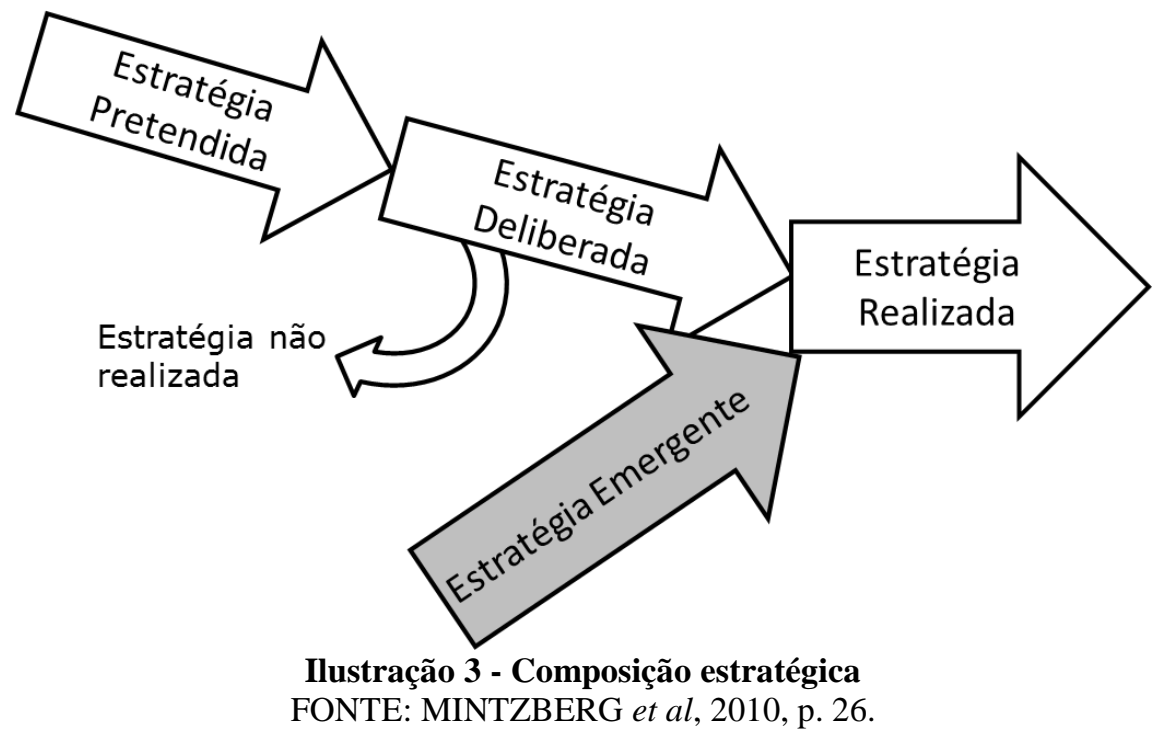

Osborn (1998, p. 487) acredita que estratégias emergentes são essencialmente reativas, surgindo em resposta a ameaças competitivas. Para o autor, a rapidez de adaptação às estratégias emergentes sustenta a agilidade competitiva. 
Mariotto (2003, p. 85) estudando as formas com que as estratégias emergem, apresenta-as emergindo de formas complementares e não conflitantes ou exclusivas, sendo estas:

- Fenômeno hierárquico, surgindo da base até o topo;

- Cognitivas, onde a organização coletivamente a percebe;

- Resultado da auto-organização em sistemas complexos, ou seja, resultado de inúmeras ações não coordenadas ; e,

- Fenômeno de aprendizado, no qual a organização corrige suas ações melhorando os próprios planos.

Mariotto (2003, p. 91) ainda explana que estratégias emergentes integram ideias provenientes de atividades diárias dos negócios, como a relação da organização com os clientes e com o mercado, surgindo ações que não haviam sido previamente planejadas, e neste contexto além de ser estruturada e mobilizada para agir com prontidão em um ambiente complexo e de rápida mudança, mas também devem saber reconhecer, avaliar e se adaptar as estratégias emergentes.

Reconhecidas as estratégias emergentes, a empresa deve ser rápida na tomada de decisão e na execução de seus planos. Para que isso aconteça, o alinhamento estratégico se torna peça chave.

\subsection{Alinhamento estratégico}

Agilidade e precisão no desenvolvimento e implantação de estratégias podem fazer a diferença entre sucesso e fracasso de organizações atuais. Além disso, a necessidade de alinhar ações rotineiras com metas estratégicas se mostra um diferencial importante na busca de solidez e lucratividade conforme apontado por Costa et al (2009, p. 2).

Para Powell (1992, p. 120) o alinhamento é um recurso estratégico capaz de produzir resultados superiores e se tornar uma forte vantagem competitiva.

Henderson e Venkatraman (1993, p. 5-9) conceituam alinhamento estratégico como a adequação estratégica e integração funcional entre ambiente externo (mercados) e interno (estrutura interna da empresa) a fim de desenvolver competências e melhorar o desempenho. 
Para Stepanovich e Mueller (2002, p. 147) o alinhamento pode ser divido em três dimensões:

- Alinhamento externo, que trata do ajuste entre a empresa e seu ambiente;

- Alinhamento interno, onde os elementos internos da empresa estão focados para a execução da estratégia; e,

- Consenso que trata do grau em que os membros da organização concordam em relação ao que deve ser feito quanto às escolhas estratégicas.

Segundo Kaplan e Norton (2006, p. 5) cabe ao alinhamento garantir sinergia entre equipes, processos, unidades de negócios e parceiros externos. Estes autores estudaram as empresas que compõem o Hall of Fame F $^{5}$ comparando-as com outros dois grupos: empresas com resultados expressivos com uso do BSC (ballancead score card) ${ }^{6}$ e empresas com resultados pouco expressivos com uso de BSC. As empresas foram classificadas de acordo com suas competências na prática de cinco princípios de gestão, conforme Ilustração 4:

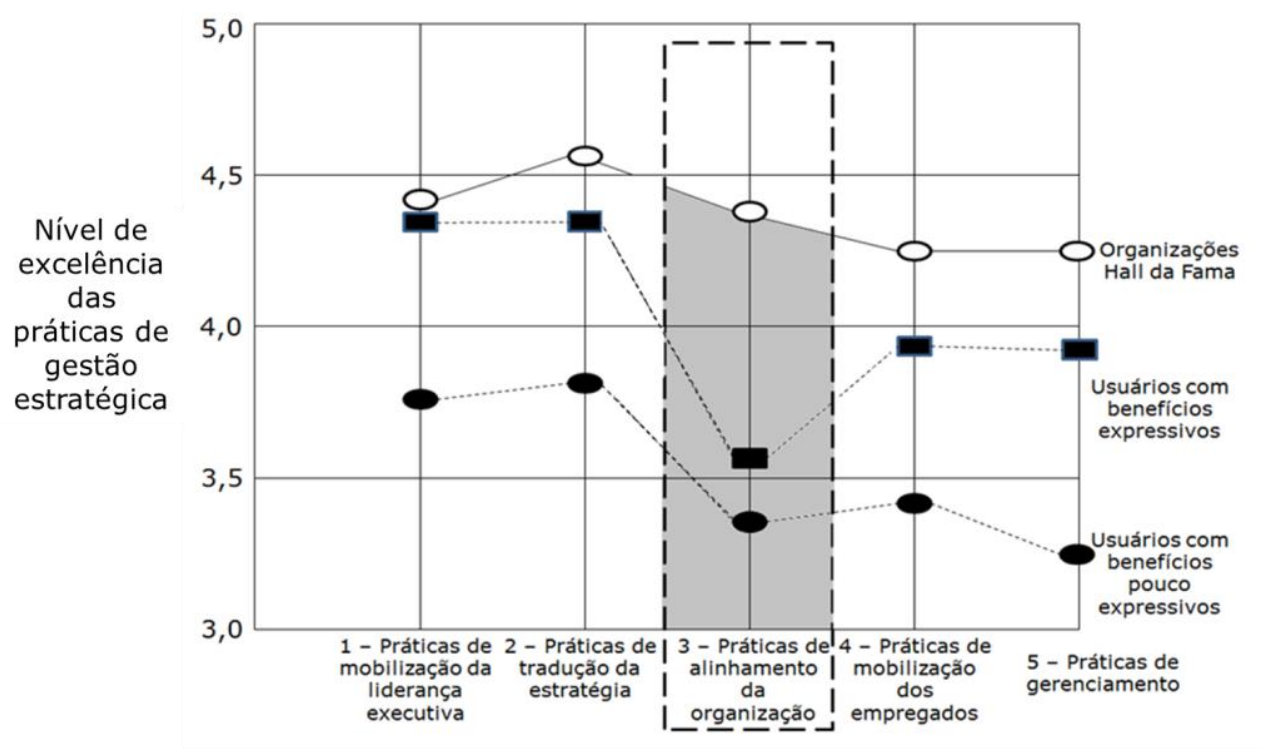

Melhores práticas de gestão

1 - "Somos péssimos", 2 - "Não somos bons", 3 - "Somos razoáveis", 4 - "Somos Bons", 5 - "Somos a melhor prática"

Ilustração 4 - Relação entre práticas de gestão e benefícios FONTE: KAPLAN; NORTON, 2006, p. 4.

\footnotetext{
${ }^{5}$ Hall of fame - Prêmio concedido pela Palladium Group Inc para empresas com resultados de performance extraordinários no uso de Ballancead Score Card - BSC.

${ }^{6}$ BSC- Ballancead Score Card - Sistema de gestão de desempenho que define metas e medição em quatro perspectivas: Financeira, cliente, aprendizado e crescimento, processos internos.
} 
A Ilustração mostra que a grande diferença entre as empresas Hall of fame e os outros grupos se encontra no alinhamento, sendo que as primeiras apresentam resultados muito superiores as dos outros dois grupos. Segundo os autores compreender como promover o alinhamento estratégico é um grande desafio capaz de trazer retorno a qualquer tipo de empresa (KAPLAN; NORTON, 2006, p. 4)

Segundo Prieto et al (2009, p. 320), “O processo de alinhamento estratégico é definido como o exercício prático de um conjunto de atividades estruturadas com a finalidade de realizar o alinhamento estratégico".

As variáveis para o alinhamento externo e interno são diferentes. Enquanto o externo se vincula a formulação da estratégia e ajuste da mesma às variáveis ambientais, o interno, objeto deste estudo, tem foco na implementação e ajuste entre estratégia e variáveis internas (PRIETO et al, 2009, p. 320).

Constando a lacuna na literatura quanto às dificuldades do alinhamento estratégico, em especial o alinhamento interno, Prieto et al (2009, p. 322) através de uma revisão de literatura, se propuseram a identificar modelos de alinhamento estratégico que servissem de referência para o alinhamento interno. Foram identificados quatro modelos adequados a estes propósitos.

Os modelos segundo Prieto et al (2009, p. 323-324) são:

- Modelo 1 - Labovitz e Rosansky: Apresentam o alinhamento como um processo de integração dos elementos da organização, sendo estes a estratégia e pessoas e clientes e processos. Os autores propõe uma ferramenta específica para diagnosticar grau de alinhamento, fazendo um autodiagnostico do alinhamento dos elementos da organização.

- Modelo 2 - Balanced Scorecard (BSC): Se baseia na disseminação do conhecimento da estratégia, por todos os níveis da organização, através de um mapa estratégico. Considera a estratégia já formulada sendo desdobrada em medidas de desempenho financeiro, perspectiva dos clientes, processos internos, aprendizado e crescimento.

- Modelo 3 - Hambrick e Canella: Apresentam o alinhamento como um processo gerencial a ser conduzido pelo estrategista. Tem por base os processos de negociação 
que visam "eliminar obstáculos, promover ajustes e convencer a respeito da importância da estratégia".

- Modelo 4 - Organizational Fitness Profiling (OFP): Considera o alinhamento um processo de mudança que envolve o aprendizado da organização na reformulação e alinhamento constante da estratégia. Tem como condição um ambiente participativo, dado que o processo é uma força tarefa.

A análise comparativa dos modelos é apresentada no Quadro 2:

Quadro 2 - Análise distintiva dos modelos de alinhamento estratégico interno

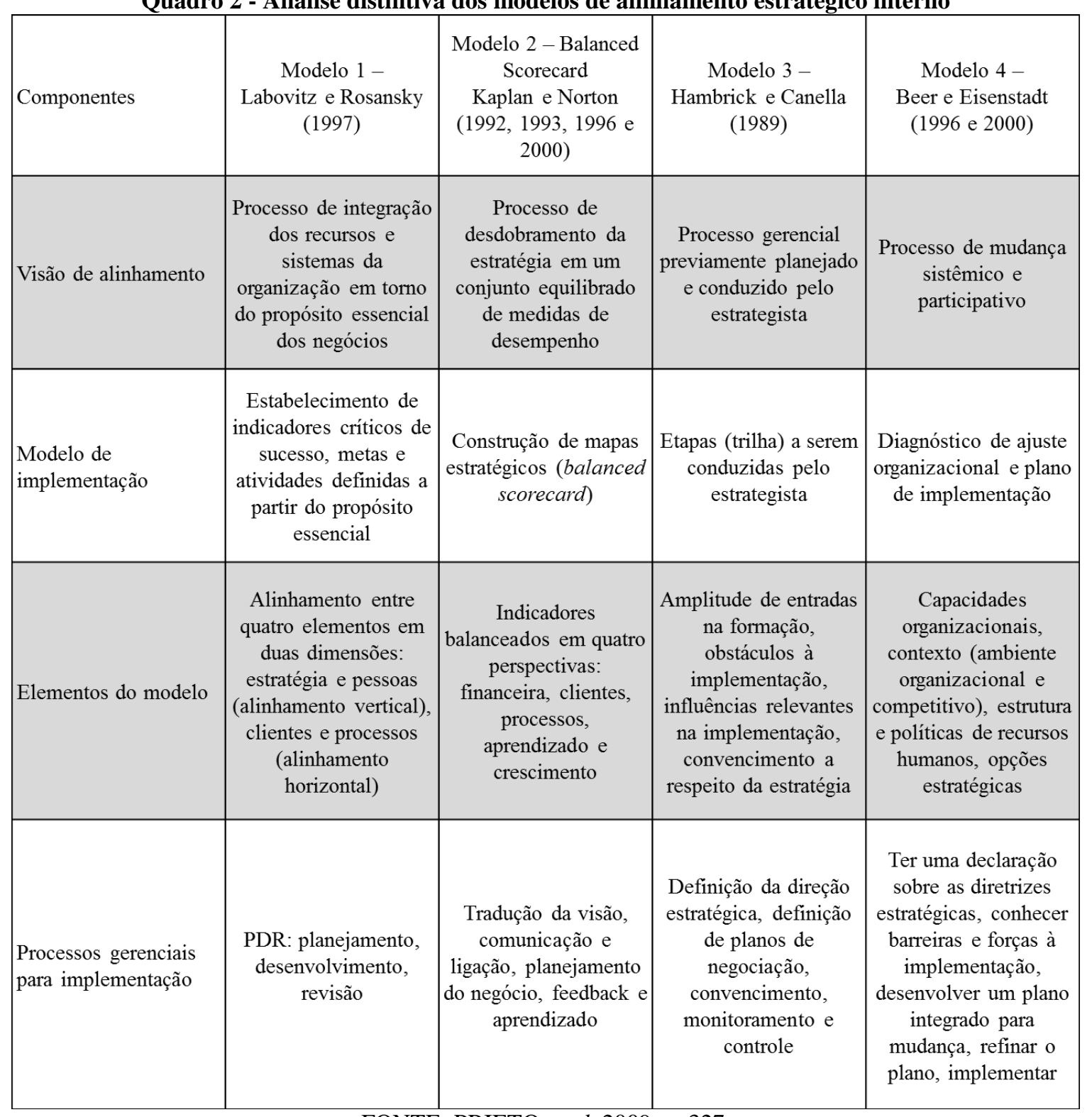


As demais características dos modelos apresentadas pelos autores são apresentadas no Quadro 3:

Quadro 3 - Características dos modelos de alinhamento estratégico

\begin{tabular}{|c|c|c|c|c|}
\hline & $\begin{array}{c}\text { Modelo } 1- \\
\text { Labovitz e } \\
\text { Rosansky (1997) }\end{array}$ & $\begin{array}{c}\text { Modelo 2- } \\
\text { Balanced } \\
\text { Scorecard } \\
\text { Kaplan e Norton } \\
(1992,1993, \\
1996 \text { e 2000) }\end{array}$ & $\begin{array}{c}\text { Modelo } 3- \\
\text { Hambrick e } \\
\text { Canella } \\
\text { (1989) }\end{array}$ & $\begin{array}{c}\text { Modelo 4- } \\
\text { Beer e } \\
\text { Eisenstadt } \\
(1996 \mathrm{e} \\
2000)\end{array}$ \\
\hline Ferramentas para medir grau de alinhamento & $\mathrm{X}$ & & & \\
\hline Fazer diagnóstico & $\mathrm{X}$ & & & $\mathrm{X}$ \\
\hline $\begin{array}{l}\text { Sistema de indicadores de avaliação de } \\
\text { evolução da estratégia em curso }\end{array}$ & $\mathrm{X}$ & $\mathrm{X}$ & & \\
\hline Análise dos aspectos intangíveis da organização & & & $\mathrm{X}$ & $\mathrm{X}$ \\
\hline Levantamento de barreiras à implementação & & & & $\mathrm{X}$ \\
\hline $\begin{array}{l}\text { Proposta de envolvimento de toda a } \\
\text { organização com a estratégia }\end{array}$ & $X$ & $\mathrm{X}$ & & \\
\hline $\begin{array}{l}\text { Papel dos executivos como negociadores da } \\
\text { estratégia em todos os níveis }\end{array}$ & & & $\mathrm{X}$ & $\mathrm{X}$ \\
\hline
\end{tabular}

FONTE: PRIETO et al, 2009 (Adaptado). 


\section{PROCEDIMENTO METODOLÓGICO}

Este capítulo tem como objetivo apresentar o procedimento metodológico utilizado na construção do presente estudo.

\subsection{Classificação de pesquisa}

Para Cohen et al (2000, p. 3) os métodos de pesquisa vão além de exercícios técnicos. A pesquisa, segundo estes autores, se difere da sabedoria comum, pois cientistas constroem suas teorias cuidadosa e sistematicamente, testam suas hipóteses empiricamente para que suas explicações tenham firme base verdadeira, além de usar técnicas e procedimentos para isolar e testar efeitos e causas, e tem como pressuposto a importante preocupação profissional com os resultados.

Para Martins e Theófilo (2007, p. 37) a metodologia tem como objetivo aperfeiçoar procedimentos e critérios utilizados na pesquisa; já o método é o caminho para chegar a determinado fim ou objetivo. Desta forma, a metodologia trabalha como a busca da realidade pela qual a ciência pode ser alcançada.

Utilizando-se desta abordagem sobre a forma de se desenvolver uma pesquisa, o presente trabalho está classificado nos seguintes pilares: quanto aos objetivos; quanto a natureza dos dados; e, quanto ao método de pesquisa.

Quanto aos objetivos, esta pesquisa tem fins exploratórios. Os estudos exploratórios segundo Gil (2006, p. 43) proporcionam visão geral acerca de determinado fato, em especial se o tema escolhido é pouco explorado. Complementando este conceito, segundo Selltiz et al (1974, p. 60), uma pesquisa é considerada exploratória quando aprofunda conhecimento sobre o tema, quando favorece um estudo posterior mais estruturado, quando esclarece conceitos, estabelece prioridades sobre pesquisas futuras e formula problema futuro para investigação mais exata ou criação de hipóteses. 
Diante disso, classifica-se este trabalho como exploratório, uma vez que aprofunda conhecimento sobre o setor de telecomunicações. Seus objetivos favorecem ainda ao caráter exploratório uma vez que seus resultados favorecem futuras pesquisas sobre o tema.

Quanto a natureza, trata-se de uma pesquisa qualitativa. A pesquisa qualitativa, segundo Martins e Theófilo (2007, p. 61) "é caracterizada pela descrição, compreensão e interpretação de fatos e fenômenos, em contrapartida à avaliação quantitativa, denominada pesquisa quantitativa, onde predominam mensurações.” Segundo Godoy (1995, p. 62) as pesquisas qualitativas tem o ambiente natural como fonte direta de dados e o pesquisador como instrumento principal.

Para a classificação do método de pesquisa, Yin (2015, p. 9) sugere a análise classificando em três questões chave:

- Forma de questão de pesquisa: Retomando a pergunta de pesquisa deste trabalho, que se forma por "Como..." e analisando a primeira situação do quadro, tem-se como opção o experimento, a pesquisa histórica e o estudo de caso.

- Exige controle dos eventos comportamentais? A análise da segunda variável, ou seja, se exige controle dos eventos comportamentais, exclui o método experimento, uma vez que não há controle de eventos na pesquisa aqui proposta.

- Enfoca eventos contemporâneos? O fato de focar em eventos contemporâneos faz com que o estudo de caso seja mais adequado em detrimento da pesquisa histórica.

Sendo assim, as situações relevantes para métodos de pesquisa, utilizadas para a classificação deste trabalho, são apresentadas no Quadro 4: 
Quadro 4 - Questões direcionadoras de classificação de pesquisa

\begin{tabular}{|l|c|c|c|}
\hline Método & $\begin{array}{c}\text { (1) Forma de questão } \\
\text { de pesquisa }\end{array}$ & $\begin{array}{c}\text { (2) Exige controle dos } \\
\text { eventos } \\
\text { comportamentais? }\end{array}$ & $\begin{array}{c}\text { (3) Enfoca eventos } \\
\text { contemporâneos? }\end{array}$ \\
\hline Experimento & $\underline{\text { Como, por quê? }}$ & Sim & Sim \\
\hline Levantamento (survey) & $\begin{array}{c}\text { Quem, o quê, onde, } \\
\text { quantos, quanto? }\end{array}$ & Não \\
\hline Análise de arquivos & $\begin{array}{c}\text { Quem, o quê, onde, } \\
\text { quantos, quanto? }\end{array}$ & Não & Sim/Não \\
\hline Pesquisa histórica & $\underline{\text { Como, por quê? }}$ & $\underline{\text { Não }}$ & Não \\
\hline Estudo de caso & $\underline{\text { Como, por quê? }}$ & $\underline{\text { Não }}$ & Sim \\
\hline
\end{tabular}

FONTE: YIN, 2015, p. 10 (Adaptado).

Após responder tais questões utilizando-se das situações relevantes para diferentes métodos de pesquisa de Yin, classifica-se que o método de pesquisa deste trabalho trata de um estudo de caso.

Yin, (2015, p. 17) define o estudo de caso em duas partes, a primeira com o escopo do estudo de caso e a segunda com as características do estudo de caso. Assim sendo:

\begin{abstract}
“1 - O estudo de caso é uma investigação empírica que investiga um fenômeno contemporâneo (“o caso") em profundidade e em seu contexto de mundo real, especialmente quando os limites entre o fenômeno e o contexto puderem não ser claramente evidentes. (...) 2 - A investigação do estudo de caso enfrenta a situação tecnicamente diferenciada em que existirão muito mais variáveis de interesse do que pontos de dados, e, como resultado conta com múltiplas fontes de evidência, com os dados precisando convergir de maneira triangular, e como resultado beneficia-se do desenvolvimento anterior das proposições teóricas para orientar a coleta e a análise de dados." (YIN, 2015, p. 17-18)
\end{abstract}

Para Eisenhardt (1989, p. 534) o estudo de caso concentra-se na dinâmica do contexto real. Ainda segundo a autora, pode ser usado para descrever, testar ou gerar teoria.

Para Flick (2013, p. 75) o principal problema do pesquisador ao fazer um estudo de caso é identificar um caso relevante para a questão de pesquisa.

O estudo de caso, apesar de cada vez mais frequente na condução de pesquisas qualitativas (MARTINS; THEÓFILO, 2007, p. 61) sofre algumas críticas e merece atenção na execução. Segundo Yin (2015, p. 222) algumas pessoas pensam no estudo de caso como último recurso, 
por: (i) falta de confiança nos procedimentos do pesquisador, que pode enviesar a pesquisa, (ii) o uso de dados qualitativos, que proporcionam medições menos robustas que dados quantitativos, e, (iii) incapacidade de generalização das descobertas do estudo .

Ainda segundo Yin (2015, p. 222), estudos mal feitos podem reunir estes pontos e recriar preconceitos ao estudo de caso, no entanto, "o uso mais sistemático e cuidadoso da pesquisa de caso pode começar a superar, senão dissipar, as preocupações”.

\subsection{A escolha do caso}

Para Yin (2015, p. 54) a escolha de um caso único possui cinco justificativas, que são ser um caso crítico, peculiar, comum, revelador ou longitudinal. Este caso trata de um caso comum, cotidiano, onde a escolha se justifica "por causa das lições que pode fornecer sobre os processos sociais relacionados a algum interesse teórico" (YIN, 2015, p. 55).

Para o atingimento dos objetivos deste estudo, utiliza-se como critério principal de escolha o potencial de contribuição do caso para a identificação do objetivo principal de pesquisa: Identificar os fatores que impulsionam o alinhamento estratégico no setor de telecomunicações, levando em consideração o aproveitamento das estratégias emergentes e agilidade de execução.

Sendo assim, a empresa escolhida, aqui denominada Beta, foi escolhida pelos seguintes motivos:

1 - O fato de existir nesta empresa experiências recentes de alinhamento de estratégia emergente, conforme apresentado no relato da experiência. Isto favorece na coleta de informações, uma vez que a situação que caracteriza o objeto deste estudo;

2 - A padronização das empresas de telecomunicações fazendo com que o estudo de um ambiente seja aplicável a outros. Ou seja, o caso escolhido demonstra que há maior ganho no estudo aprofundado de um ambiente do que no estudo superficial de vários, e; 3 - Facilidade de acesso à organização por parte da pesquisadora. 


\section{3}

\section{Definição da amostra e processo de coleta}

Segundo Flick (2013, p. 82) a amostragem é a estratégia que garante que o estudo tenha os casos "certos", ou seja, que permitem que casos generalizados da amostra sejam representativos para a população que representam, ou que foram encontrados e incluídos os casos mais instrutivos para a pesquisa.

Para Marconi e Lakatos (2002, p. 41) o problema da amostragem é escolher uma parte, ou amostra, onde os resultados obtidos sejam representativos à população total, caso esta fosse verificada. Segundo eles (p. 52), as amostras podem ser divididas em probabilísticas, que podem ser submetidas a tratamentos estatísticos, e não probabilísticas, onde a escolha não é aleatória e não podem ser objeto de tratamento estatístico.

Este trabalho usará de amostra não probabilística intencional. $\mathrm{Na}$ amostra intencional o pesquisador tem interesse em determinados elementos da população, que pelo seu entender são mais representativos (MARCONI; LAKATOS, 2002, p. 52). Com relação a amostra intencional:

\footnotetext{
A suposição básica da amostra intencional é que, com bom julgamento e estratégia adequada, podem ser escolhidos os casos a serem incluídos e, assim, chegar a amostras que sejam satisfatórias para as necessidades da pesquisa. (...) se os critérios de julgamento na escolha da amostra forem corretos, uma amostra intencional deverá trazer melhores resultados para a pesquisa do que uma por conveniência. (MATTAR, 1994, p. 286).
}

Sob o olhar destas teorias e considerando os objetivos da pesquisa, este trabalho seguiu os seguintes critérios para definição da amostra:

1 - Selecionados para serem investigados devem possuir cargos de liderança, dado o maior acesso que os mesmos têm à estratégia da empresa e a responsabilidade dos mesmos no alinhamento para execução;

2 - Selecionados para serem investigados devem possuir mais de um ano de empresa, podendo assim conhecer melhor seu funcionamento e por consequência as questões que permeiam este trabalho. 
Com relação ao processo de coleta, este se dá pela técnica de entrevista, que segundo Martins e Theófilo (2007, p. 86) é a técnica utilizada para coleta de informações, dados e evidências com o objetivo de entender o significado que os entrevistados atribuem a questões e situações em contexto que não foram estruturados antes.

Yin (2015, p. 117) considera a entrevista como uma das técnicas mais importantes para o estudo de caso e que "entrevistados bem informados podem proporcionar insights importantes sobre esses assuntos ou ações (...) podem fornecer atalhos para a história prévia destas situações, ajudando-o identificar outras formas relevantes de evidência".

O processo de coleta de informações é guiado pelo protocolo do estudo de caso para este estudo e neste trabalho compreende o plano da Quadro 5:

Quadro 5 - Plano de coleta de dados

\begin{tabular}{|c|c|c|c|}
\hline Método & Fonte & \multicolumn{1}{c|}{ Dados } & Objetivo \\
\hline & & & \\
& & & \\
Entrevista & Lideres da & Emergência da estratégia; & Entender o processo de \\
alinhamento de & Alinhamento da estratégia emergente, e; \\
& organização & - Condução para execução & para execução. \\
& & & \\
\hline
\end{tabular}

Para Boni e Quaresma (2005, p. 75) a principal vantagem da entrevista aberta ou semiestruturada é que quase sempre produzem uma melhor amostra da população de interesse, tendo um índice de resposta mais abrangente, elimina-se a dificuldade de escrever de algumas pessoas e possibilita-se a correção de engano por meio dos informantes. Além disso, tem como vantagem a proximidade entre entrevistador e entrevistado possibilitando que assuntos mais delicados sejam abordados. As limitações do modelo estão ligadas a tempo e recursos do pesquisador.

Portanto, com relação ao roteiro para as entrevistas, a presente pesquisa se baseou no estudo aprofundado da literatura pertinente ao tema e na elaboração de uma entrevista em profundidade que direcionasse a construção do instrumento de coleta. Sendo assim, as entrevistas foram semiestruturadas, utilizando-se de questões orientadoras, que direcionaram os entrevistados aos 
pontos de interesse desta pesquisa, porém, deixando-os livres para transcorrer sobre o tema. (Anexo 1)

\subsection{Análise dos dados}

De forma geral, segundo Martins e Theófilo (2007, p. 69), “A análise de dados consiste em examinar, classificar e, muito frequentemente, categorizar os dados, opiniões e informações coletadas, ou seja, a partir das proposições, teoria preliminar e resultados encontrados, construir uma teoria que ajude a explicar o fenômeno sob estudo".

Segundo Yin (2015, p. 146) a melhor preparação para a condução da análise de um estudo de caso é possuir uma estratégia analítica geral, ligando os dados do estudo com os conceitos de interesse, para que estes forneçam uma orientação na análise dos dados. A partir da estratégia geral o autor sugere cinco técnicas de análises de dados (YIN, 2015, p. 147-172):

- Combinação de padrão: Estabelece lógica entre um padrão descoberto na pesquisa e padrão previsto antes da coleta

- Construção de explicação: Analisa os dados do estudo construindo explicação sobre o caso;

- Análise de séries temporais: Conduzida em experimentos e nos quase experimentos;

- Modelos lógicos: Estipula e operacionaliza um encadeamento complexo de acontecimento; e,

- Síntese cruzada de casos: Aplica-se somente a casos múltiplos.

Com base na literatura apresentada, a análise de dados tem como técnica a construção da explicação do comportamento da empresa estudada, no que tange a tratativa das estratégias emergentes.

Yin (2015, p. 172) reforça que, independente da técnica, o pesquisador deve cuidar para que a análise seja da mais alta qualidade. Para que isso aconteça o pesquisador deve seguir os princípios apresentados na Ilustração 5: 


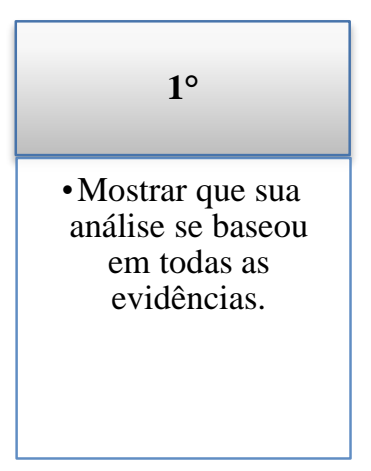

Ilustração 5 - Princípios da boa pesquisa de ciência social FONTE: YIN, 2015, p. 172-3 (Adaptado).

Para Martins e Theófilo (2007, p. 69) a qualidade da análise será notada no tratamento e discussões das interpretações concorrentes e exposição dos aspectos mais significativos do estudo e possíveis laços com outras pesquisas assemelhadas.

"A confiabilidade de uma medida é a confiança que a mesma inspira." (MARTINS; THEÓFILO, 2007, p. 13). Para Yin (2015, p. 51) a confiabilidade tem como meta minimizar erros e parcialidades do estudo.

Uma das formas de se aferir confiabilidade a um estudo de caso é o uso do protocolo de pesquisa. Martins e Theófilo definem o protocolo como:

\footnotetext{
O protocolo se constitui em um conjunto de códigos, menções e procedimentos suficientes para se replicar o estudo, ou aplicá-lo em outro caso que mantém características semelhantes ao estudo original. O protocolo oferece condição prática para se testar a confiabilidade do estudo, isto é, obterem-se resultados assemelhados em aplicações sucessivas a um mesmo caso. (MARTINS; THEÓFILO, 2007, p. 10).
}

Além da confiabilidade, Yin $(2015$, p. 88) o protocolo tem um papel importante na orientação do pesquisador para a realização da coleta de dados e condução da pesquisa como um todo.

Este estudo de caso tem todo o seu processo guiado pelo protocolo de estudo de caso no Anexo 1. 


\section{O ESTUDO DE CASO}

Este capítulo apresenta o caso estudado e os dados coletados.

\subsection{Introdução ao caso}

Este estudo foi realizado uma multinacional de telecomunicações que atua em todo o território brasileiro. A empresa aqui é denominada Beta a fim de preservação da identidade da instituição.

A empresa, subsidiária de um grupo europeu, foi fundada no fim dos anos 90, porém sua visibilidade nacional acontece no início dos anos 2000 com o aumento considerável do número de municípios atendidos. Em 2016 conta com mais de 10.000 funcionários.

A empresa figura entre as principais operadoras de telecomunicações do Brasil, oferecendo serviços de telefonia móvel e fixa para pessoas físicas e jurídicas.

\subsection{Introdução às entrevistas}

Após estudo bibliográfico e metodológico o estudo de caso se deu utilizando-se de entrevistas ocorridas durante o primeiro semestre de 2016. Os entrevistados foram contatados por telefone e as entrevistas foram feitas presencialmente ou por telefone. As entrevistas foram gravadas com o consentimento dos entrevistados.

O foco das entrevistas se ateve ao fato de entender como os entrevistados reagiam a partir do momento que uma alteração estratégica acontecia, visando a execução das mesmas. Em suma, o objetivo principal foi entender de que forma alinhavam as estratégias emergentes com todos os elementos da cadeia responsáveis por sua execução.

As entrevistas abrangeram dois grandes blocos de questões: 
- Buscar o perfil do entrevistado; e,

- Abordar questões técnicas desta pesquisa.

As entrevistas foram realizadas até que fosse encontrado um consenso de dados que dessem possibilidade de análise ao caso.

\subsection{As entrevistas}

O conteúdo aqui analisado provém de seis entrevistas aplicadas em funcionários da empresa estudada, com cargos de especialistas e gerentes, com tempo médio de trabalho na empresa de 6 anos e 4 meses, e de 10 anos e 4 meses de experiência no mercado de telecomunicações. Os entrevistados foram escolhidos em diferentes áreas: comunicação, trade marketing, vendas, engenharia de redes, tecnologia da informação e projetos. Os perfis são apresentados no Quadro 6:

Quadro 6 - Perfil dos entrevistados

\begin{tabular}{|c|c|c|c|c|}
\hline Entrevistado & Formação & Cargo & $\begin{array}{c}\text { Tempo na } \\
\text { empresa } \\
\text { (anos) }\end{array}$ & $\begin{array}{c}\text { Tempo em } \\
\text { telecom } \\
\text { (anos) }\end{array}$ \\
\hline A1 & Administração & $\begin{array}{l}\text { Especialista Sênior em } \\
\text { Comunicação e Mídia }\end{array}$ & 05 & 05 \\
\hline A2 & Administração & Gerente de Trade Marketing & 10 & 10 \\
\hline A3 & Engenharia Elétrica & Gerente de Vendas & 07 & 25 \\
\hline A4 & $\begin{array}{c}\text { Engenharia de } \\
\text { Telecomunicações }\end{array}$ & $\begin{array}{c}\text { Gerente de } \\
\text { Implantação de Rede }\end{array}$ & 06 & 08 \\
\hline A5 & $\begin{array}{l}\text { Ciência da } \\
\text { Computação }\end{array}$ & $\begin{array}{c}\text { Especialista de Tecnologia da } \\
\text { Informação }\end{array}$ & 06 & 06 \\
\hline A6 & Matemática & Gerente de Projetos e Processos & 04 & 08 \\
\hline
\end{tabular}

A fim de mostrar o cenário de entrevistas apresenta-se primeiramente os dados obtidos na primeira entrevista que direcionou as demais, denominada A1, e sem seguida as demais entrevistas que são denominadas de A2 a A6. 


\subsubsection{Entrevista A1}

A fim de maior compreensão prática do alinhamento estratégico da empresa estudada, a primeira entrevista foi realizada no contexto do primeiro caso apresentado na introdução deste trabalho, a alteração no modelo de lojas para atendimento de pessoas físicas, relembrado pela Ilustração 1:

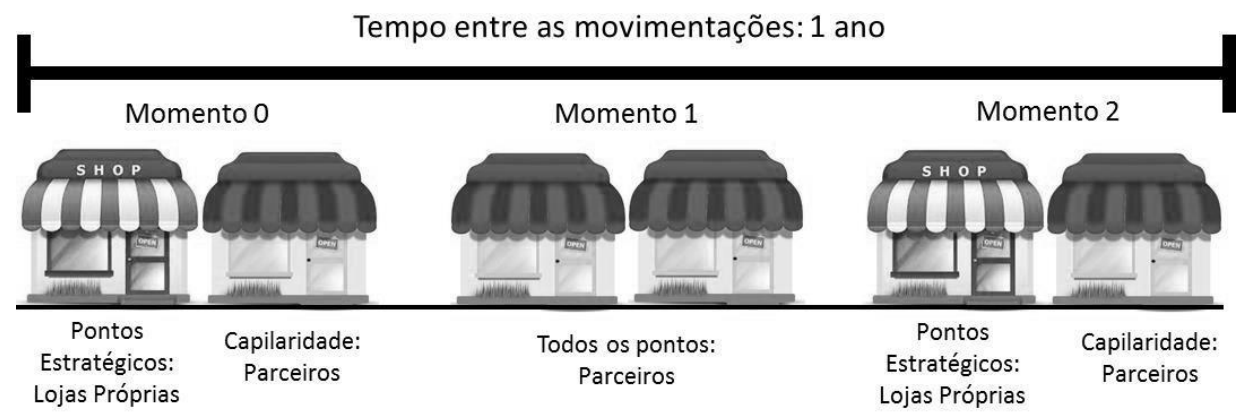

Ilustração 1 - Movimentação dos tipos de loja da Empresa de Telecomunicação

A entrevista, realizada com o gestor responsável pela retomada das lojas como próprias, foi realizada de forma aberta e se iniciou com o mesmo relembrando o caso, reiterando todos os pontos apresentados já relatados neste trabalho. $\mathrm{O}$ entrevistado frisou a velocidade da alteração da estratégia, ou seja, partir de um modelo de lojas próprias para lojas terceiras e o retorno de lojas terceiras para lojas próprias em apenas um ano, bem como a velocidade com que estas alterações tiveram que acontecer na prática.

Uma vez tomada a decisão de mudança de modelo, ou seja, retomar como operação própria lojas que estavam sendo operadas por terceiros, o entrevistado foi o responsável por alinhar todas as áreas impactadas e fazer com que a mudança acontece-se na prática. Assume-se aqui que o houve alinhamento uma vez que a mudança de modelo aconteceu com sucesso, o que significa que todas as áreas impactadas, de alguma forma foram alinhadas à estratégia e executaram seu papel no plano.

Quando questionado especificamente sobre como as outras áreas impactadas, além da sua (vendas), souberam da necessidade de mudança e como se engajaram na execução, o mesmo elencou alguns fatores importantes, como sua autonomia em liderar o projeto, podendo tomar as ações necessárias sem a necessidade de aprovações superiores, o que se cascateia para a 
maioria dos funcionários, que têm autonomia para negociar suas entregas e por fim as próprias características da empresa, que acostumada com situações similares, mudanças estratégicas com a necessidade de agilidade na execução, faz com que seus funcionários sejam mais receptivos e proativos em agir prontamente.

Um ponto que deve ser destacado é a importância da participação das demais áreas na construção do plano das atividades a serem desenvolvidas, uma vez que o gestor responsável sabia quais áreas seriam impactadas na alteração de modelo, porém só as próprias poderiam dizer qual o nível de impacto e que atividades deveriam ser executadas. A síntese da forma com que o evento apresentado foi executado pela empresa de telecomunicações investigada é apresentada na Ilustração 6:

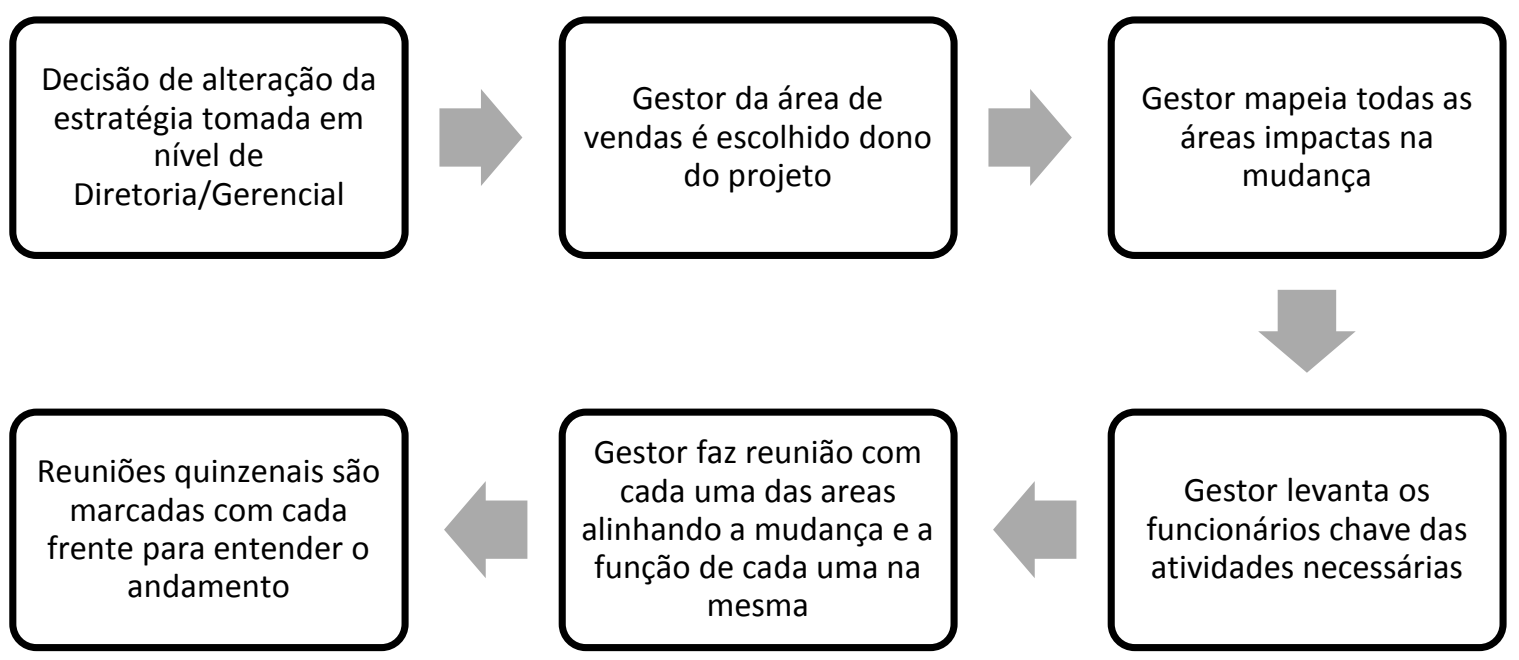

Ilustração 6 - Processo de execução de mudança estratégica em um caso de uma empresa de telecomunicações

O entrevistado relatou que a empresa não adotava, à época do evento estudado, ou seja, até 2012, nenhuma ferramenta formal para casos como este, e que a maneira apresentada aqui foi a desenvolvida por ele para enfrentar o desafio que lhe foi passado.

Por fim, reforçou que a ausência de um modelo a ser seguido onerou seu trabalho, dado que houve perda de tempo no planejamento sobre como colocar o projeto em prática, ou seja, em desenvolver o processo apresentado acima, bem como a morosidade em levantar áreas impactadas e funcionários chaves, por outro lado, a mesma ausência de um modelo lhe proporcional desenhar um que fosse adequado exatamente as suas necessidades. 
O entrevistado destacou que ainda que a forma trabalhada por ele fosse adequada, não há uma gestão do conhecimento, fazendo que novos funcionários passando por situações semelhantes devam descobrir por si próprio qual a melhor maneira de agir.

\subsubsection{Entrevistas A2 a A6}

As entrevistas seguintes a esta seguiram o formato semiaberto buscando entender os seguintes pontos:

- Como o entrevistado reage a partir de uma alteração estratégica focando na execução da mesma;

- Como todas as áreas/pessoas impactadas são identificadas e alinhadas;

- Que características da empresa favorecem ou dificultam este trabalho; e,

- Se há uso de alguma ferramenta ou metodologia neste processo.

Estes pontos foram desdobrados em oito questões que são apresentadas no Anexo 1.

A primeira pergunta teve a intenção de validar a emergência de estratégias. Quando questionados sobre mudanças após o planejamento estratégico da empresa ter sido fechado, fazendo com quem a execução se diferisse do inicialmente planejado, as respostas foram unânimes. O planejamento inicial se altera em várias oportunidades e com frequência, deixando evidente a incidência das estratégias emergentes na empresa.

Para que os entrevistados pudessem responder as demais perguntas com maior propriedade, foi solicitado que relembrassem uma situação em que estivessem envolvidos em uma alteração estratégica. Seguem dois relatos ilustrativos, um onde a mudança estratégica foi impulsionada pela ação da concorrência e em outro por uma recomendação ANATEL:

A2: A gente teve um lançamento de oferta em 2015 que a gente tinha todo um planejamento pra fazer o lançamento em vinte e cinco dias. Então ao longo dessa janela a gente tinha um prazo de treinamento, de produção de material, tecnologia de informação, toda uma janela para a entrada de uma oferta, e aí a ficamos sabendo que a concorrência ia lançar uma oferta muito parecida em cinco dias, aí a gente teve que alterar todo nosso cronograma pra fazer o lançamento antes da concorrência de uma oferta que tinha sido a gente que tinha desenvolvido. 
A5: Teve um exemplo grande que a gente fez o desdobramento dos clientes que tinham que ser bloqueados quando atingissem a cota de internet, ai todo mundo era bloqueado, teve todo um projeto pra fazer este processo, a gente começou a fazer pra alguns DDD's e não chegou a terminar porque no meio deles a gente teve que mudar a estratégia porque a ANATEL falou que a gente não podia bloquear os clientes, ai a gente teve que na verdade desfazer a execução, tendo que ter todo um plano de projeto pra desfazer tudo isso e entrar com uma mecânica nova (...) O processo tinha levado dois meses pra fazer e a gente teve que refazer no horizonte de duas semanas.

Usando como exemplo os relatos, buscou-se entender como a situação foi conduzida para que fosse executada.

Neste contexto, apesar dos diferentes cenários, nota-se uma característica comum: no momento em que a necessidade de mudança é identificada, todos os processos param e um replanejamento de urgência é feito. Este processo pode ser exemplificado a seguir através da fala da entrevista A4:

A4: Na verdade a forma da empresa é: deu problema, joga todo mundo numa sala de reunião e faz reunião, uma vez por dia, ou várias vezes por dia, dependendo da necessidade.

As variáveis são rapidamente analisadas e replanejadas, em todas às vezes necessárias, através de uma reunião com todas as partes envolvidas. Em alguns casos acontecem reuniões diárias de status para acompanhamento destas mudanças; em outros, após o realinhamento, cada parte simplesmente seguia com sua função.

A importância dos agentes, ou dos funcionários envolvidos também se mostra importante. Os relatos mostram autonomia dos agentes em decidir qual o melhor caminho a seguir e também a importância de se ter bons funcionários, com boa rede de contatos e navegabilidade corporativa para conseguir direcionar os trabalhos:

A3: A execução funciona primeiro quando se é rápido em entender o que deve ser feito e se aciona as pessoas certas. Com anos de empresa você já sabe quem devem acionar, e as pessoas já são acostumadas a isso. A dinâmica de, por conhecimento próprio saber quem são os 
envolvidos, chamar uma reunião e juntos decidirmos como seguir é bem presente na empresa. Eu tenho esta liberdade, não preciso esperar que meu chefe ou outra pessoa de cargo maior se envolva. A partir do momento que fazemos esta primeira reunião, cada um já sabe qual a sua parte no trabalho, e aí fazemos outras reuniões de controle.

Quando questionados sobre como a identificação das áreas envolvidas e o alinhamento entre estas foi feito novamente, aparece a importância das pessoas envolvidas no processo e as reuniões. Um processo a ser considerado que surge na entrevista A2 é a questão do cronograma inverso, e a A6 reforça a importância dos agentes:

A2: (...) E aí enfim, a hora que a gente entendeu o que estava acontecendo e qual era a urgência que a gente tinha pra fazer esta mudança, na mesma hora a gente chamou o gerente de canal comercial e o diretor da operação e montou-se toda uma estratégia ali, então, um cronograma de trás pra frente mas todo mundo envolvido e o diretor comercial dando o direcionamento de como a gente ia fazer a tocada regional do ponto de vista da estratégia macro.

A6: Quando o projeto teve que mudar de direção o líder do projeto já sabia quem eram os focais que ele tinha que consultar para fazer a análise de impacto da alteração e foi responsável por envolver todo mundo e gerenciar os planos de acompanhamento diária das equipes. Não era só uma pessoa, era uma equipe, mas tinha uma pessoa principal. Esta pessoa fez toda diferença, o cara inclusive é um dos melhores, é muito bom o cara.

A pergunta seguinte buscou entender que características da empresa facilitavam ou dificultavam o trabalho dos entrevistados nas situações relatadas.

A2: Então, a mesma característica que facilita é a característica que atrapalha a gente. Por exemplo, a gente tem uma dificuldade muito grande do ponto de vista de processo dentro da companhia, então quando a gente tem um acontecimento deste a gente não tem muito molde do que seguir, por mais que este seja um ponto fora da curva, por várias vezes a gente se depara com situações destas, a gente sabe o problema, identifica, mas a gente não tem um ponto a ponto ali de como seguir, ou de como agir em uma situação destas, por outro lado, o que dificulta um pouco, você ter que criar e começar do zero é um dos grandes pontos a favor da empresa, como você não tem processo você tem o poder de criação do processo que você tá inventando na hora, então, eu decidi que eu ia fazer um treinamento em um lugar com três 
turmas de 500 pessoas e tirar todo mundo de loja ao meio do dia e eu consegui fazer entendeu? Ao mesmo tempo em que eu não tenho processo pra fazer as coisas me ajuda que eu posso fazer e qualquer jeito talvez sirva.

A3: A abertura, as pessoas podendo expor as ideias, explicar os riscos sem serem julgadas, por não terem feito algo, por não terem identificado riscos mais cedo, ou sinais de mudança, ajudam muito neste trabalho. Não digo que em todas as áreas são assim, depende da liderança do projeto ou da área líder, mas quando isso acontece as alterações são contornadas de forma muito mais fácil.

A4: A disposição em comprar o risco. Muitas vezes tomamos decisões que não temos certeza se é o melhor caminho, mas preferimos agir rápido. Caso se descubra depois que não era o melhor jeito, começamos de novo. Os processos são abertos, então há liberdade de ação e os erros não são, na maioria das vezes, julgados, então a velocidade acaba sendo um ganho importante em situações como estas.

A5: Falta de processos estruturados, o que não amarra a gente e liberdade de ação. Poder de decisão, dentro da sua esfera de trabalho é um dos valores da empresa, então a maioria das pessoas se sente confortável em decidir o que deve ser feito em situações de mudanças estratégicas.

A6: Buscar uma solução rápida. Analisadas as variáveis, o que se pode fazer com isso agora? Não há tempo para estudos aprofundados, ou ter que pedir aprovação para todo mundo. Se faz o melhor com o que se tem na hora. Pode ser que dê errado, mas aí se repensa de novo.

Outras duas perguntas de validação foram feitas aos entrevistados: se eles usavam algum típico de métrica ou indicador nos processos de alteração estratégica, ou se usavam algum método ou ferramenta para gerenciar o mesmo processo. Para estas perguntas todas as respostas foram negativas, ou seja, os entrevistados não usam e também não conhecem na empresa nenhum tipo de controle para as situações relatadas. 


\section{ANÁLISE DO CASO}

Neste capítulo são apresentadas as análises realizadas frente ao conteúdo coletado nas entrevistas anteriormente relatadas.

As entrevistas apresentaram relatos diversificados, porém, de forma bastante clara, demonstraram a interferência de estratégias emergentes na empresa estudada. Os relatos mostraram que a todo momento planos precisam ser ajustados ou até mesmo criados a fim de que a empresa tenha condições de se adaptar as exigências regulatórias, do mercado ou de seus agentes internos.

Neste contexto dinâmico do mercado de telecomunicações, a alta incidência de estratégias emergentes fez com que a empresa e, por consequência, seus funcionários se acostumassem a este tipo de situação. Os entrevistados trouxeram a emergência de estratégias como algo cotidiano, o que resulta na forma como estes as tratam.

A forma geral de condução das estratégias emergentes visando o alinhamento e a execução foi a mesma em todos os relatos. Há sempre um líder, ou um grupo que lidere a mudança e esta pessoa é a responsável pelo alinhamento entre áreas e pessoas impactadas. O capital humano nesta ação de conduzir estratégias emergentes visando o alinhamento e a execução torna-se fator-chave e sua importância deve ser considerada. Ou seja, o conhecimento que os funcionários têm do funcionamento da empresa e sua rede de contatos são os responsáveis para que o alinhamento aconteça e no tempo necessário.

Na prática as pessoas responsáveis pelas áreas impactadas são acionadas, faz-se uma reunião com todas as pessoas envolvidas e realinha-se a estratégia. Outras reuniões de controle podem ser feitas ou não, em casos onde a urgência é maior, realinha-se e cada qual executa sua parte, não há tempo para controles intermediários. Uma prática importante que surge nestes cenários é o uso do cronograma inverso, fazendo a programação das atividades a partir da data em que deve ser entregue. 
A forma de alinhamento e condução das estratégias emergentes na empresa estudada é sintetizada na Ilustração 7:

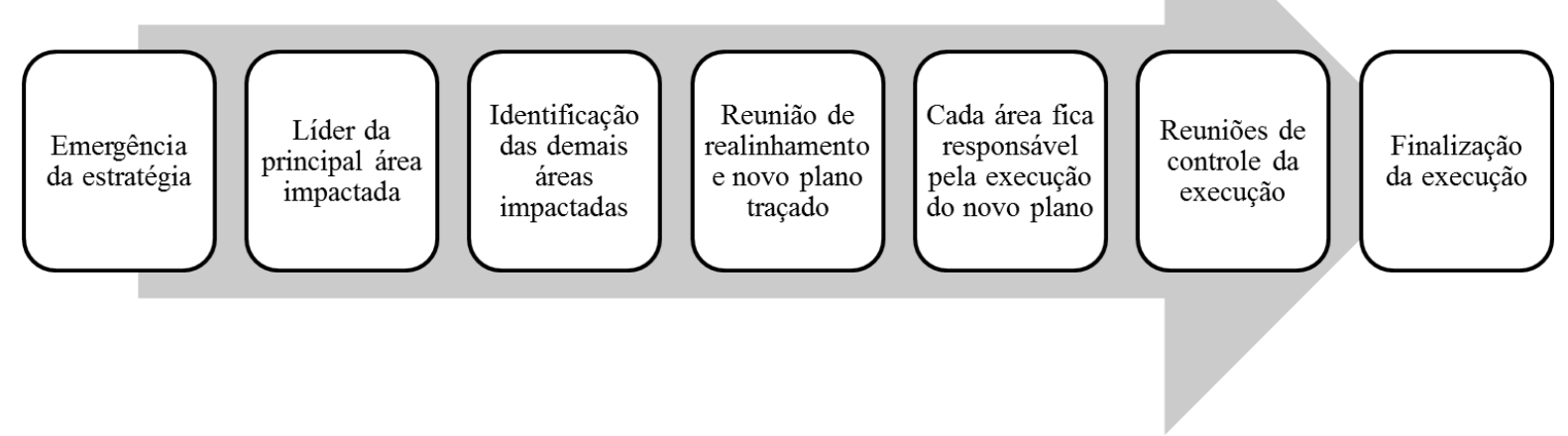

Ilustração 7 - Alinhamento de estratégias emergentes em empresa de Telecomunicações

Estando a estratégia alinhada, a execução traz características importantes da empresa que possibilitam sucesso na execução de estratégias emergentes.

A primeira característica diz respeito a autonomia e poder de decisão dos funcionários. Notase que em suas esferas de trabalho as pessoas podem tomar decisões sobre qual melhor caminho seguir. Não há necessidade de uma extensa lista de aprovações dentro da própria hierarquia e tão pouco com outras áreas. O funcionário, ou o grupo deles, que está de frente com o problema faz a análise das variáveis, decide, e a execução começa quase que automaticamente.

A segunda característica é a falta de processos estruturados. Se por um lado isso pode apresentar dificuldades, por outro, possibilita que em situações onde a agilidade é importante, exista a liberdade de se criar um processo que seja mais adequado à situação.

A terceira característica é ter a agilidade como prioridade nos momentos de decisão. O quão rápido um plano pode ser executado é levado em consideração. Opções menos rápidas são preteridas diante de outras que podem ser executadas com maior agilidade.

Por fim, e ligada a todas as outras, toma-se a predisposição ao risco. A falta de processos, autonomia, priorização da agilidade mostram o quanto a empresa está disposta a se arriscar. Reforça-se este cenário com os depoimentos onde o errar e refazer aparece muitas vezes. 
Melhor tomar uma decisão ágil e não sendo a mais acertada readequar do que esperar uma longa análise buscando certeza de qual o melhor caminho.

As características da empresa que impulsionam o alinhamento e execução das estratégias emergentes são sintetizadas na Ilustração 8:

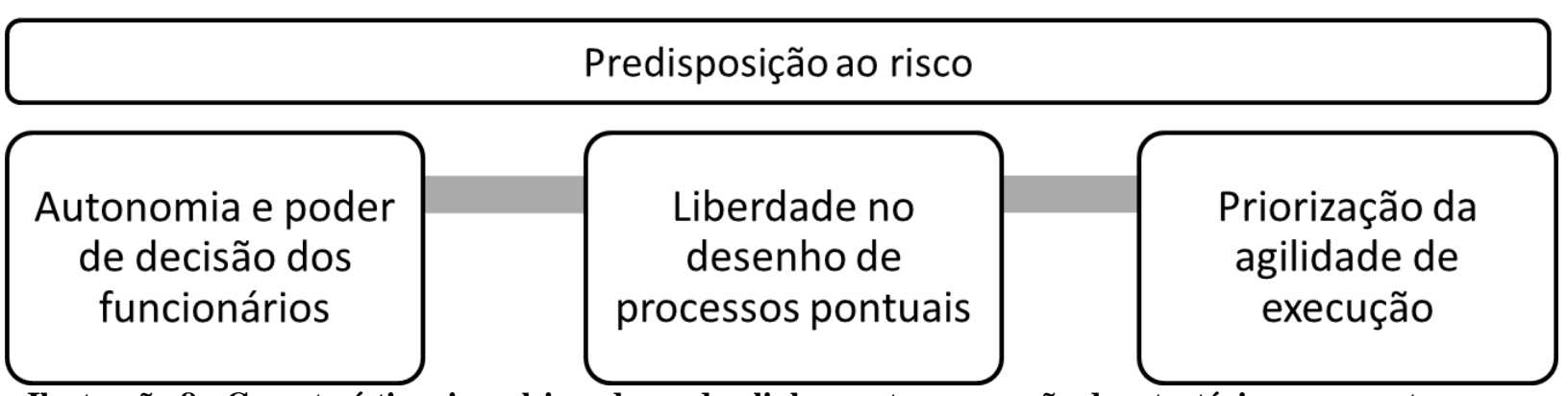

Ilustração 8 - Características impulsionadoras do alinhamento e execução de estratégias emergentes em uma empresa de telecomunicações

Além da emergência de estratégias, outros pontos que foram unanimidade entre os entrevistados são a ausência de indicadores, métricas ou ferramentas que auxiliem os gestores a conduzir estas situações de mudança.

\subsection{Análise de modelos teóricos comparados ao estudo de caso}

Este item trata da análise de modelos teóricos sobre alinhamento estratégico comparando-os ao estudo de caso investigado a fim de que se possa propor um modelo recomendável quando se trata de alinhamento estratégico para telecomunicações.

Analisadas todas as características da empresa estudada versus as ferramentas de alinhamento estratégico apresentadas como referência teórica, tem-se:

- Modelo 1 - Labovitz e Rosansky (LABOVITZ; ROSANSKY, 1997): verifica-se um modelo focado em diagnóstico de alinhamento e em métricas de alinhamento;

- Modelo 2 - Balanced Scorecard (BSC) (KAPLAN; NORTON, 1992; 1993; 1996; 2000): tem-se o ponto de partida em uma estratégica estabelecida a partir da qual se traça desdobramentos e controles; 
- Modelo 3 - Hambrick e Canella (HAMBRICK; CANELLA, 1989): verifica-se a importância do papel do estrategista, fazendo as negociações necessárias para a implementação da estratégia;

- Modelo 4 - Organizational Fitness Profiling (OFP) (BEER; EISENSTADT, 1996; 2000): tem-se um cenário onde o aprendizado da organização e o esforço coletivo são importantes para o alinhamento e execução da estratégia.

Por este cenário dos modelos, o modelo 1 (Labovitz e Rosansky) não seria o mais adequado, uma vez que diagnóstico de alinhamento não se mostrou uma das preocupações para a empresa, e ainda que o modelo não seja focado apenas nisso, esta parte do processo demandaria tempo adicional, fator crítico para o sucesso dos projetos da empresa estudada.

O modelo 2 (Balanced Scorecard (BSC)) parte de uma estratégia bastante estruturada e que necessariamente deve ser desdobrado em cinco pilares. Fato é que na empresa estudada nem sempre a estratégia está totalmente estruturada e nem sempre será possível o desdobramento dos cinco pilares, dado que, em processos internos, por exemplo, se esforçar para alcançar a perspectiva do cliente, nem sempre é necessário para o sucesso da implementação e ainda demandaria tempo.

Já os modelos 3 (Hambrick e Canella) e 4 (Organizational Fitness Profiling (OFP) apresentam características interessantes aos olhos do caso, uma vez que o 3 coloca o estrategista com papel principal no desdobramento, e o 4 reforça o aprendizado e o ambiente colaborativo da empresa para o sucesso do alinhamento. As duas visões são adequadas para o caso estudado.

Analisando os componentes dos modelos pela ótica do estudo de caso tem-se:

- Visão de alinhamento: Todos os modelos entendem o alinhamento estratégico como um processo, porém para o Modelo 1 é um processo de integração, para o 2 de desdobramento, para o 3 um processo de negociação e convencimento e para o 4 um processo de mudança de participativo. Todas estas visões poderiam ser adequadas ao caso, mas os modelos 3 e 4 estão mais alinhados à dinâmica da empresa;

- Modelo de implementação: O Modelo 1 estabelece indicadores de sucesso, metas e atividades. O Modelo 2 constrói mapas estratégicos, o 3 etapas ou trilhas que devem ser 
conduzidas pelo estrategista e o 4 um diagnóstico de ajuste e plano de implementação. De formas diferentes os modelos trazem formas de traçar atividades essenciais à implementação, porém os aspectos dos modelos 3 e 4, se assemelham mais a dinâmica do caso apresentado;

- Elementos do modelo: O modelo 1 foca-se em estratégias e pessoas, clientes e processos; o modelo 2 em financeira, clientes, processos, aprendizado e crescimento; o modelo 3 em obstáculos, influências relevantes na implementação e convencimento à respeito da estratégia; o modelo 4 nas capacidades organizacionais, contexto, estrutura e políticas de recursos humanos, opções estratégicas. Aqui tem-se uma vantagem nos modelos 3 e 4 uma vez que deixam os elementos apresentados são mais abrangentes e podem se adequar a qualquer alteração estratégica que a empresa venha a passar;

- Processo gerencial para a implementação: $O$ modelo 1 fala de planejamento, desenvolvimento e revisão; o modelo 2 de tradução da visão, comunicação e ligação, planejamento do negócio, feedback e aprendizado; o modelo 3 de definição da direção estratégica, definição de planos de negociação, convencimento, monitoramento e controle e o modelo 4 de ter uma declaração sobre as diretrizes estratégicas, conhecer barreiras e forças à implementação, desenvolver um plano integrado para mudança, refinar o plano, implementar. Todos estes processos são adequados ao caso estudado.

Quando parte-se para a análise das características de cada modelo, tem-se de forma geral, modelos 1 e 2 focados em aspectos tangíveis da organização e com métricas estruturadas de desdobramento e modelos 3 e 4 focados em aspectos intangíveis e colocando as pessoas, seja o estrategista principal ou o grupo, como foco do trabalho. Outro aspecto importante que destaca os modelos 3 e 4 é a identificação das barreiras à implementação, aspecto não abordado pelos modelos 1 e 2.

$\mathrm{Na}$ análise apresentada até o momento os modelos 3 e 4 se destacam para o caso estudado. A volatilidade do ambiente de telecomunicações, o que se reflete nas estratégias faz que aspectos intangíveis, como pessoas, por exemplo, tenham papel importante no desdobramento da estratégia. Estes fatores são melhor considerados nos modelos 3 e 4. Outros aspectos importantes para o caso, que são abordados por estes modelos é o papel do estrategista e da empresa como um todo no desdobramento estratégico. Estes dois aspectos são muito presentes no caso relatado. 
Um ponto importante difere os modelos 3 e 4 na análise feita por Prieto et al (2009). Para os autores o modelo 4, sendo mais flexível e menos estruturado, dando autonomia a quem toma decisão em favor da agilidade, é mais favorável a ambientes turbulentos, onde os fatores intangíveis precisem ser prioritariamente questionados e revisados. Já o modelo 3 é mais adequado a empresas que tenham maior conhecimento de suas capacidades onde o estrategista já possua uma visão ampla dos fatores de influência à estratégia e cuide da implementação através das atividades.

Esta diferenciação faz com que o modelo 4, Organizational Fitness Profiling (OFP), seja escolhido como o mais adequado ao caso estudado, alinhamento de estratégia emergente em operadora de telecomunicações, dado que este trata de ambiente turbulento onde o papel e a autonomia do estrategista são essenciais a implementação da estratégia. O modelo é apresentado na Ilustração 9:

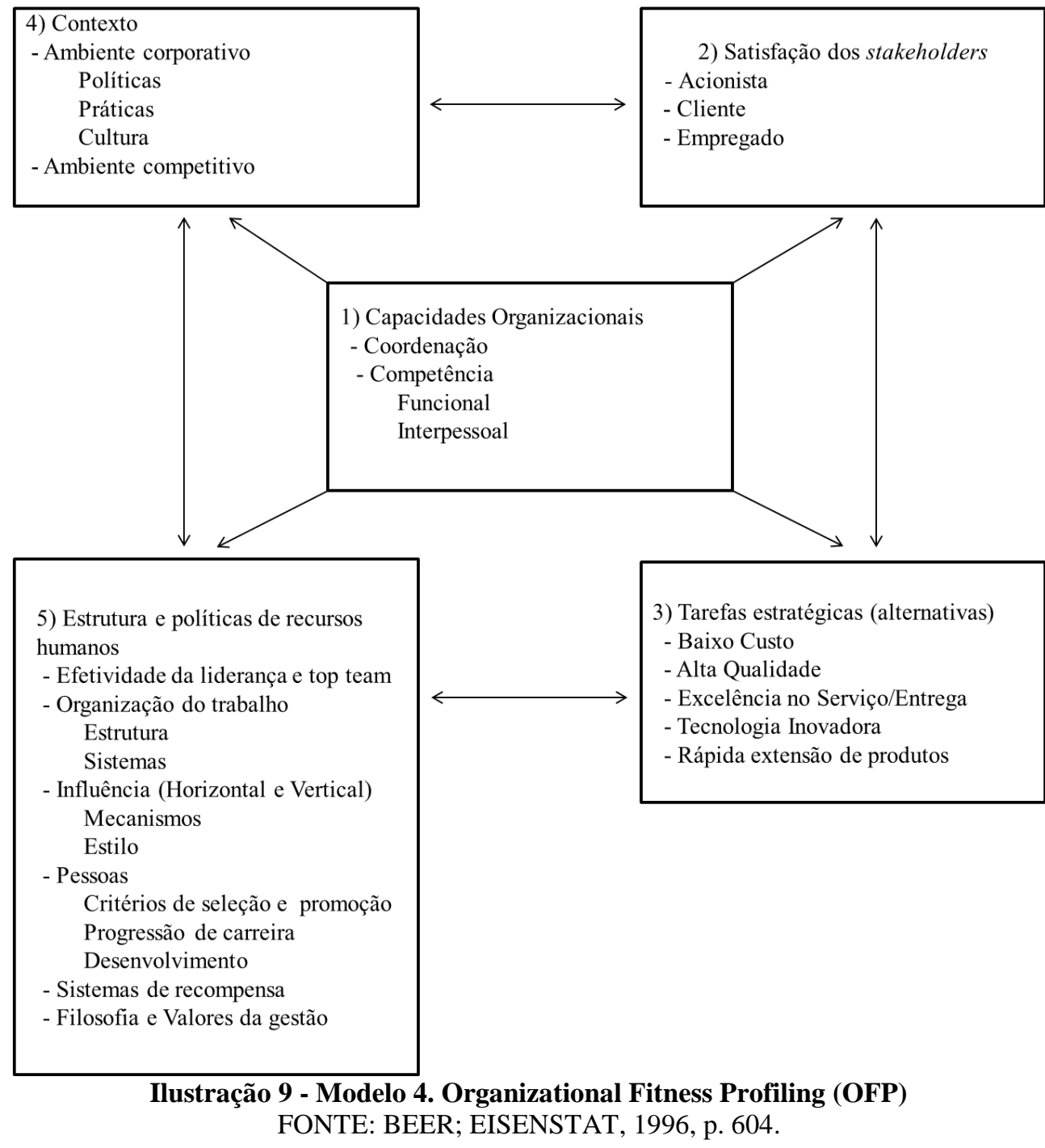




\section{CONCLUSÕES E RECOMENDAÇÕES}

A dinâmica do mercado de telecomunicações impõe às empresas a necessidade de estarem sempre alertas ao mercado e de promoverem alterações estratégicas constantes para que mantenham, ou ainda, melhorem suas capacidades competitivas.

Neste sentido, o caso apresentado se mostra apropriado ao estudo do alinhamento estratégico, uma vez que este discorre sobre uma análise e contextualização da teoria aplicada à prática de uma empresa, demonstrando a importância do mesmo para o sucesso da implementação de uma estratégia.

Analisado o objetivo principal deste trabalho que é Investigar e analisar como o alinhamento de estratégias emergentes é feito em uma operadora de telecomunicações, considerando todas as particularidades do setor conclui-se que não foi encontrado um processo formal estruturado, mas sim um processo intuitivo e próprio guiado por algumas características da empresa que são facilitadoras deste processo.

Analisados todos os depoimentos dados através de entrevistas nota-se que quatro características bastante fortes para que o alinhamento estratégico acontece-se: Autonomia dos agentes, liberdade no desenho de processos pontuais, priorização da agilidade e pré-disposição ao risco.

A forma com que o alinhamento de estratégias emergentes é feito em uma operadora de telecomunicações, bem como as características que o impulsionam são sintetizados na Ilustração 10: 


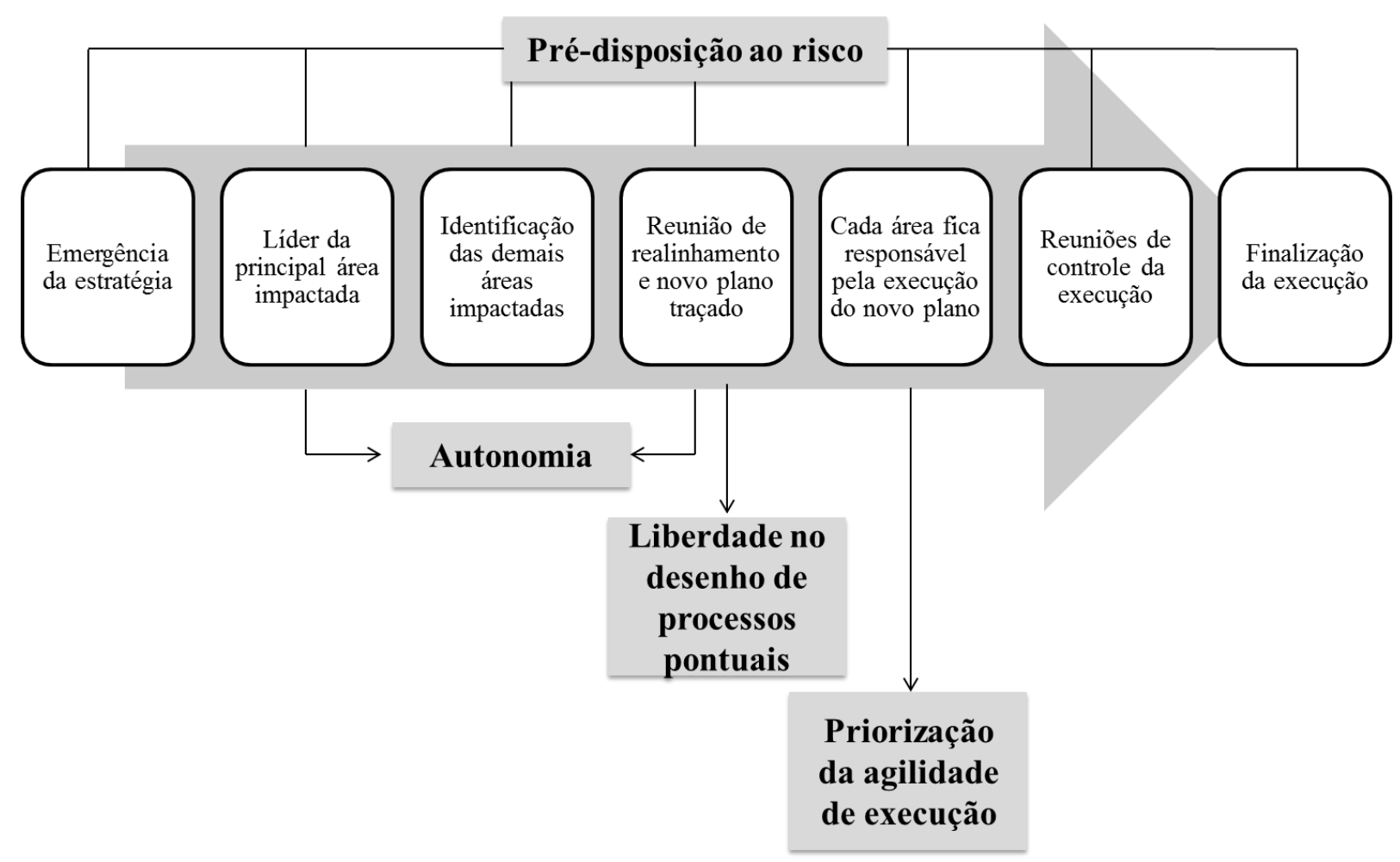

Ilustração 10 - Processo de alinhamento de estratégias emergentes e características impulsionadoras

Desta forma responde-se aqui ao objetivo principal desta pesquisa, que era investigar e analisar como o alinhamento de estratégias emergentes é realizado em uma operadora de telecomunicações, bem como aos objetivos específicos de identificar fatores que impulsionam o alinhamento estratégico no setor de telecomunicações, levando em consideração o aproveitamento das estratégias emergentes e agilidade de execução e aaprofundar conhecimento sobre as práticas do mercado de telecomunicações no que tange o alinhamento de estratégias emergentes.

Na busca por práticas deste mercado que possam contribuir com melhores práticas em outros mercados, entende-se (ou evidencia-se) a partir deste estudo que empresas que busquem maior agilidade no alinhamento e execução de estratégias emergentes podem ou devem se ater aos seguintes pontos: Estimular o poder de decisão de seus funcionários dentro de seu escopo de responsabilidades, buscar maior flexibilização de processos, priorizar a agilidade na execução e por fim, estarem dispostas a correr riscos.

Por fim, buscando apontar com base na teoria elementos que possam aprimorar as práticas atuais de alinhamento estratégico, apontou-se que o modelo de alinhamento estratégico de 
Beer e Eisenstat (1996) seria, no contexto deste estudo de caso, o mais indicado para o caso de empresa vir a buscar uma ferramenta formal de alinhamento estratégico. Não se pode ignorar, porém, que todas as ferramentas possuem pontos fortes e a junção delas ainda apresenta lacunas.

Sendo assim este trabalho contribui, portanto, para um maior entendimento sobre o contexto de uma empresa de telecomunicações, apresentando as características que a possibilita ser ágil no alinhamento e execução de estratégias emergentes. Estas características podem ser mais profundamente estudadas em busca de caminhos que melhorem o alinhamento e execução de estratégias, tanto em telecomunicações, quanto em outros mercados.

Em termos de limitações, este trabalho apresenta como limitação o fato de se restringir a uma única empresa. Recomenda-se para futuros trabalhos uma análise aprofundada de outras empresas do mesmo setor buscando validação das respostas aqui encontradas.

Ainda que uma ferramenta de alinhamento estratégico aqui tenha sido apontada, sugere-se também para estudos futuros o estudo de uma ferramenta integrada que reúna os pontos fortes e trate as lacunas dos modelos apresentados. 


\section{REFERÊNCIAS}

AGÊNCIA NACIONAL DE TELECOMUNICAÇÕES - ANATEL. Relatórios Consolidados - Indicadores de 1997 a 2001. Dados. 06/02/2015. Disponível em: <http://www.anatel.gov.br/dados/index.php/2015-02-04-18-43-59/numeros-do-setorindicadores-de-1997-a-2001>. Acesso em: 12/02/2015.

ARRUDA, Felipe. 3G e 4G: entenda as diferenças de infraestrutura. Tecmundo. 4G. 30/04/2013. Disponível em: <http://www.tecmundo.com.br/4g/39145-3g-e-4g-entenda-asdiferencas-de-infraestrutura.htm $>$. Acesso em 13/03/2016.

ASSOCIAÇÃO BRASILEIRA DE TELECOMUNICAÇÕES - TELEBRASIL. Diagnóstico, cenários e ações para o Setor de Telecomunicações no Brasil: 2014-2020. SindiTelebrasil, jul. 2011. Disponível em: <http://www.telebrasil.org.br/posicionamentos/estudo/326diagnostico-cenarios-e-acoes-para-o-setor-de-telecomunicacoes-no-brasil-julho-de-2011>. Acesso em: 10/10/2015.

O Setor de Telecomunicações no Brasil - Uma Visão Estruturada. 2014. Disponível em: <http://www.telebrasil.org.br/component/docman/doc_download/1545-o-setor-detelecomunicacoes-no-brasil-visao-estruturada-2015?Itemid=>. Acesso em 24/11/2015.

BEER, Michael; EISENSTAT, Russell. A. Developing an organization capable of implementing strategy and learning. Human Relations, v. 49, n. 5, p. 597-603, 1996.

The silent killers of strategy implementation and learning. Sloan Management Review,v. 41, n. 4, p. 29-40, 12 p., Summer, 2000.

BONI, Valdete; QUARESMA, Sílvia Jurema. Aprendendo a entrevistar: Como fazer entrevistas em Ciências Sociais. Em Tese. Revista Eletrônica dos Pós-Graduandos em Sociologia Política da UFSC, v. 2, n. 1(3), p. 68-80, jan./jul. 2005.

BRASIL. Lei Geral de Telecomunicações - Lei n. 9.472, de 16/07/1997. Disponível em: <http://www.planalto.gov.br/ccivil_03/leis/19472.htm>. Acesso em: 24/11/2014.

COHEN et al. Reserch Methods in Education. 5th ed. London: Routledge Falmer, 2000.

COSTA, George Silva et al. Uma Discussão Sobre Critérios Competitivos da Produção em Empresas que Implantaram a Construção Enxuta. In: XXIX ENCONTRO NACIONAL DE ENGENHARIA DE PRODUÇÃO, 2009. Anais... Salvador: ENEGEP, 2009. 
COUTINHO, Diogo R., Entre eficiência e equidade: A universalização das telecomunicações em países em desenvolvimento. Revista Direito GV, v. 1, n. 2, p 137-160, jun./dez. 2005.

EISENHARDT, Kathleen M. Building Theories from Case-Study Research. Academy of Management Review, v. 14, n. 4, p. 532-550, oct. 1989.

FISCHMANN, Adalberto A.; ALMEIDA, Martinho I. R. Planejamento estratégico na prática. São Paulo: Atlas, 1991.

FLICK, Uwe. Introdução à Metodologia de Pesquisa. Um Guia para Iniciantes. Porto Alegre: Penso, 2013.

GIL, Antônio. C. Métodos e técnicas de pesquisa social. 5. ed. São Paulo: Atlas, 2006.

GODOY, Arilda S. Introdução à pesquisa qualitativa e suas possibilidades. Revista de Administração de Empresas. São Paulo, v. 35, n. 2, p. 57-63, 1995.

HENDERSON, John C.; VENKATRAMAN, H. Strategic alignment: leveraging information technology for transforming organizations. IBM Systems Journal, v. 32, n. 1, p. 4, 1993.

KAPLAN, Robert S.; NORTON, David P. The balanced scorecard: measures that drive performance. Harvard Business Review, v. 70, n. 1, p. 71-79, 1992. $142,1993$.

. Putting the balanced scorecard to work. Harvard Business Review, v. 71, n. 5, p. 134Using the balanced scorecard as a strategic management system. Harvard Business Review, v. 74, n. 1, p. 75-85, 1996.

Having Trouble With Your Strategy? Then map it. Harvard Business Review, v. 78, iss. 5, p. 167-176, 2000.

. Alinhamento: usando o Balanced Scorecard para criar sinergias corporativas. Rio de Janeiro: Elsevier, 2006

LABOVITZ, George.; ROSANSKY, Victor. The power of alignment: how great companies stay centered and accomplish extraordinary things. New York: John Wiley \& Sons, 1997.

MARCONI, Marina A.; LAKATOS, Eva M. Técnicas de pesquisa. 5. ed. São Paulo: Editora Atlas, 2002. 
MARIOTTO, Fábio L. Mobilizando Estratégias Emergentes. Rev. adm. empres., v. 43, n. 2. p. 78-93, abr./maio/jun. 2003.

MARTINS, Gilberto. A.; THEÓFILO, Carlos. R. Metodologia da Investigação Científica para Ciências Sociais Aplicadas. São Paulo, Atlas, 2007.

MATTAR, Fauze. N. Pesquisa Mercadológica. São Paulo: Atlas, 1994.

MINTZBERG, Henry et al. Safári de estratégia: um roteiro pela selva do planejamento estratégico. 2. ed. Porto Alegre: Bookman, 2010.

NERIS JR. et al. Trajetórias tecnológicas da indústria de telefonia móvel: um exame prospectivo de tecnologias emergentes. Economia e Sociedade. Campinas, v. 23, n. 2 (51), p. 395-431, 2014.

OPERADORAS buscam alternativas para SMS. Estadão. Link. 30/01/2014. Disponível em: $<$ http://blogs.estadao.com.br/link/ascensao-de-aplicativos-faz-operadoras-buscaremalternativas-para-sms>. Acesso em: 15/03/2015.

OSBORN, Charles S. Systems for sustainable organizations: emergente strategies, interactive controls and semi-formal information. Journal of Management Studies, v. 35, n. 4, p. 481509, 1998.

PORTER, Michael E. What is strategy? Harvard Business Review, v. 74, n. 6, p. 61-78, nov./dec. 1996.

POWELL, Thomas C. Organizational alignment as competitive advantage. Strategic management journal, v. 13, n. 2, p. 119-134, 1992.

PRIETO, Vanderli C. et al. Análise comparativa de modelos de alinhamento estratégico. Produção, v. 19, n. 2, p. 317-331, 2009.

QUINN, James B. Estratégias para mudanças. In: MINTZBERG, Henry et al. O processo da estratégia: contextos e casos selecionados. 4. ed. São Paulo: Artmed - Bookman, 2006.

SELLTIZ, Claire. et al. Métodos de pesquisa nas relações sociais. São Paulo: EDUSP, 1974.

SILVA, Casturina J. et al. Estratégia como Ferramenta nas Organizações Sociais: Um Estudo Sobre Organizações do Terceiro Setor na Região do Vale do Rio dos Sinos. In: COSTA, B. K.; ALMEIDA, M. I. R. (Coord.). Estratégia Perspectivas e Aplicações. São Paulo: Atlas, 2002. 
STEPANOVICH, Paul L.; MUELLER, J. D. Mapping Strategic Consensus. Journal of Business and Management. Fort Collins, v. 8, iss. 2, p. 147-164, 2002.

SUZUKI, Akira. Huawei prepara rede 5G para a Copa do Mundo da Rússia, em 2018. Tecmundo. 5G. 19/11/2014. Disponível em: <http://www.tecmundo.com.br/5g/66165huawei-prepara-rede-5g-copa-mundo-russia-2018.htm>. Acesso em: 24/11/2014.

TELECO. Inteligência em Telecomunicações. 2016. Diponível em: <http://www.teleco.com.br/ncel.asp>. Acesso em: 10/07/2016.

TELEFÓNICA compra Vivo por 7,5 bilhões de euros. Veja. Veja.com, Economia. Da Redação. 28/07/2010. Disponível em: <http://veja.abril.com.br/noticia/economia/telefonicacompra-vivo-por-7-5-bilhoes-de-euros>. Acesso em: 01/04/2016.

TELEFÔNICA Vivo conclui compra da GVT. Tele.Síntese. Operadoras. Da Redação. 28/05/2015. Disponível em: <http://www.telesintese.com.br/telefonica-vivo-conclui-comprada-gvt/>. Acesso em: 30/05/2016.

THOMSON, Amy; KHRENNIKOV, Ilya. Bilionário russo quer expandir negócios com fusão Oi e TIM. Revista Exame. Exame.com, Negócios, 2015. Disponível em: $<$ http://exame.abril.com.br/negocios/noticias/bilionario-russo-quer-expandir-negocios-comfusao-oi-e-tim>. Acesso em: 10/03/2016.

YIN, Robert K., Estudo de caso: planejamento e métodos. 5. ed. Porto Alegre: Bookman, 2015.

WIZIACK, Julio. Justiça determina bloqueio do WhatsApp em todo o Brasil por 48 horas. Folha de S. Paulo. Mercado, 16/12/2015. Disponível em: <http://www1.folha.uol.com.br/mercado/2015/12/1719934-justica-determina-bloqueio-dowhatsapp-em-todo-brasil-por-48-horas.shtml>. Acesso em: 17/03/2016.

; FRIEDLANDER, David. Fusão de Oi com TIM não sai e aguça apetite de fundos dos

EUA. Folha de S. Paulo. Mercado, 26/02/2016. Disponível em: <http://www1.folha.uol.com.br/mercado/2016/02/1743474-fusao-de-oi-com-tim-nao-sai-eaguca-apetite-de-fundos-dos-eua.shtml>. Acesso em: 11/06/2016. 


\section{ANEXO 01 - PROTOCOLO DE PESQUISA}

\section{A - Visão Geral do estudo de caso e finalidade do protocolo}

O estudo de caso a ser realizado visa embasar um maior entendimento sobre como o alinhamento estratégico de estratégias emergentes acontece em uma empresa de telecomunicações. Para que este objetivo seja atingido, foi definido o objetivo, questões de pesquisa e a lógica do estudo a ser seguida.

\section{A1 - Missão e metas do estudo}

O estudo de caso realizado visa aprofundar o entendimento sobre alinhamento de estratégias emergentes no setor de telecomunicações, compreendendo como este alinhamento acontece, que características da empresa estudada possibilitam este alinhamento, o que podemos aprender com a prática da mesma e também em que a teoria pode contribuir para melhoria da prática.

\section{A2 - Questões, hipóteses e proposições}

A pergunta que direciona este estudo é: Como o alinhamento de estratégias emergentes é feito em uma operadora de telecomunicações?

Dado o cenário de dinamismo do setor de telecomunicações, que é impactado pela emergência de estratégias provenientes tanto da competitividade entre as empresas, quanto de fatores externos como a agência reguladora do setor, as empresas são constantemente obrigada a redirecionar seus planos e executá-los de forma rápida para que consigam manter sua competitividade.

Partindo-se de duas premissas embasadas pelo relato da experiência: (i), que as estratégias emergentes são executadas com sucesso, (ii) de alguma forma o alinhamento estratégico acontece; este estudo tem como objetivo: 
- Investigar e analisar como o alinhamento de estratégias emergentes é feito em uma operadora de telecomunicações, considerando todas as particularidades do setor.

E como objetivos específicos:

- Identificar os fatores que impulsionam o alinhamento estratégico no setor de telecomunicações, levando em consideração o aproveitamento das estratégias emergentes e agilidade de execução;

- Aprofundar conhecimento sobre as práticas do mercado de telecomunicações no que tange o alinhamento de estratégias emergentes,

- Identificar práticas deste mercado que contribuir com melhores práticas em outros mercados, e;

- Averiguar elementos provenientes da experiência prática que possam contribuir com as teorias exploradas.

- Apontar, com base na teoria, oportunidades de melhoria nas atuais práticas de alinhamento estratégico do mercado de telecomunicações;

\section{A3 - Estrutura teórica}

Para responder a pergunta de pesquisa, optou-se pelo referencial teórico que segue a lógica do assunto abordado: estratégia, estratégia emergente e alinhamento estratégico.

\section{A4 - Papel do protocolo}

O uso do protocolo, segundo Yin (2015, p. 88), orienta o pesquisador na realização da coleta de dados, além de ser importante para aumento de confiabilidade do estudo. 


\section{B - Procedimentos de coleta de dados}

O estudo de caso possibilita a utilização de múltiplos métodos de coleta de dados, sendo a entrevista o método escolhido aqui.

\section{B1 - Perfil dos entrevistados}

\begin{tabular}{|c|c|c|c|c|}
\hline Entrevistado & Formação & Cargo & $\begin{array}{c}\text { Tempo na } \\
\text { empresa } \\
\text { (anos) }\end{array}$ & $\begin{array}{c}\text { Tempo em } \\
\text { telecom } \\
\text { (anos) }\end{array}$ \\
\hline A1 & Administração & $\begin{array}{l}\text { Especialista Sênior em } \\
\text { Comunicação e Mídia }\end{array}$ & 05 & 05 \\
\hline A2 & Administração & Gerente de Trade Marketing & 10 & 10 \\
\hline A3 & Engenharia Elétrica & Gerente de Vendas & 07 & 25 \\
\hline A4 & $\begin{array}{c}\text { Engenharia de } \\
\text { Telecomunicações }\end{array}$ & $\begin{array}{c}\text { Gerente de } \\
\text { Implantação de Rede }\end{array}$ & 06 & 08 \\
\hline A5 & $\begin{array}{l}\text { Ciência da } \\
\text { Computação }\end{array}$ & $\begin{array}{c}\text { Especialista de Tecnologia da } \\
\text { Informação }\end{array}$ & 06 & 06 \\
\hline A6 & Matemática & Gerente de Projetos e Processos & 04 & 08 \\
\hline
\end{tabular}

\section{B2 - Plano de coleta de dados}

As entrevistas semiestruturadas, tiveram como fonte seis executivos da empresa estudada, escolhidos por seu potencial de contribuição ao estudo do caso. O trabalho em campo buscou respostas para os seguintes pontos:

1) Como o entrevistado reage a partir de uma alteração estratégica focando na execução da mesma;

2) Como todos os as áreas/pessoas impactadas são identificados e alinhadas;

3) Que características da empresa favorecem ou dificultam este trabalho;

4) Se há uso de alguma ferramenta ou metodologia neste processo. 


\section{B3 - Questões orientadoras}

As entrevistas se guiaram pelo seguinte roteiro:

- Formação

- Cargo

- Tempo na Empresa (anos)

- Tempo em Telecomunicações (anos)

1. Após o planejamento estratégico de sua empresa/área ter sido fechado, acontecem alterações ou por algum motivo a execução se difere do que foi planejado?

2. Pode me relatar um exemplo de situação onde isso aconteceu e você esteve pessoalmente envolvido?

3. Usando como exemplo a situação relatada, como você conduziu para que fosse executada?

4. E como fez para identificar/alinhar todas as áreas/pessoas impactadas?

5. Você usa algum tipo de indicador ou métrica no processo?

6. Houve sucesso na execução? Sim/Não? A que atribui.

7. Que características da sua empresa/ambiente de trabalho facilitam ou dificultam seu trabalho nestas situações?

8. Você faz uso de um método ou ferramenta neste processo?

\section{B4 - Análise dos dados}

Os dados são analisados pela técnica de construção de explicação, onde os dados são analisados buscando construir explicação sobre o caso. 


\section{C - Guia para o relatório de estudo de caso}

O relatório deste estudo foi estruturado de forma analítico-linear. Esta composição é considerada padrão e a mais recomendada por Yin (2015), quando a audiência é constituída por pesquisadores ou banca de dissertação ou tese. 